Solid State Chemistry

Elsevier Editorial System(tm) for Journal of

Manuscript Draft

Manuscript Number: JSSC-18-1712R1

Title: Surface Nickel particles generated by exsolution from a perovskite structure

Article Type: Research Paper

Keywords: Ni particles; perovskites; exsolution process; reduction conditions; TEM

Corresponding Author: Dr. Fabiola Nerina Aguero, PH.D

Corresponding Author's Institution: Intequi

First Author: Fabiola Nerina Aguero, PH.D

Order of Authors: Fabiola Nerina Aguero, PH.D; Ana M Beltran; María A Fernandez; Luis E Cadus

Abstract: LaAl1-xNixO3 (with $\mathrm{x}=0.05$ and 0.2 ) perovskite oxides were successfully synthesized and its behavior under reduction atmosphere was studied. HRTEM and STEM studies, coupled to HAADF and EDX detection, allowed to evidence the $\mathrm{Ni}$ exsolution process to the surface of the solid and to build nano-catalytic centers. The size of these centers is independent of the reduction conditions in the range studied. The high specific surface of the raw material, its porosity and the structure defects could be responsible of the low temperature at which the exsolution process starts. The content of $\mathrm{Ni}$ dopants allows the control of $\mathrm{Ni}$ centers size on the surface and the synthesis method provides Ninanoparticles strongly anchored to the resultant support. 


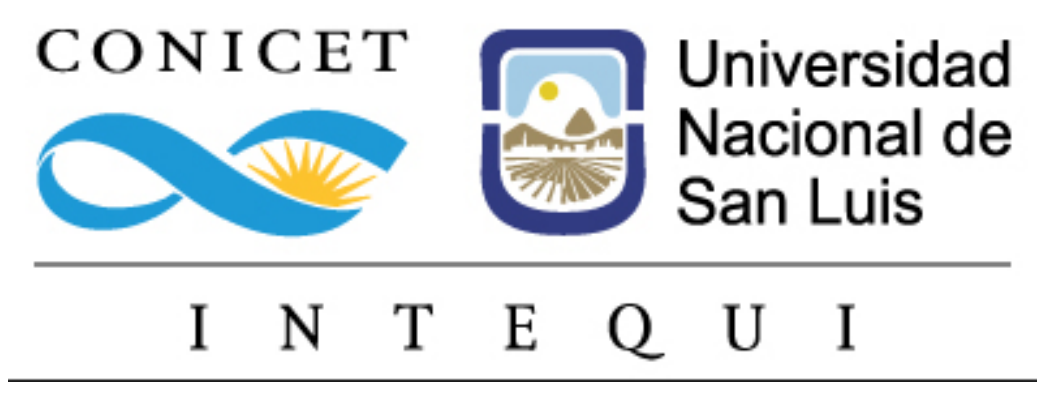

San Luis, Argentina, Febrary 7th, 2019.

Journal of solid state chemistry

Editor

Dear Editor, I am pleased to submit the revised version of the manuscript entitled "Surface Nickel particles generated by exolution from a perovskite structure" by Fabiola N. Aguero, Ana M. Beltrán, María Asunción Fernández, Luis E. Cadús.

Yours Faithfully,

\author{
Dra Fabiola Nerina Aguero \\ INTEQUI (UNSL - CONICET) Almirante Brown 1455 \\ 5700 San Luis Argentina +54 (0266) 4520300 int 3137 \\ e-mail: fnaguero@unsl.edu.ar
}


Reviewer \#1: In the present study LaA11-xNixO3 (with $\mathrm{x}=0.05$ and 0.2 ) perovskite oxides were synthesized and its behavior under reduction atmosphere was studied. They claimed that the Ni exsolution to the surface of the solid built nano- centers independent on the reduction conditions. Although the idea of self-formation of Ninano-centers from ex-perovskite is nice idea, the present work is lack of substantial study, which is temperature programmed reduction/temperature programmed oxidation cycles. In addition to use the terminology "Ni- nano-catalytic centers", it should be tested for catalytic test reaction, which is also missed in the present study. -I suggest to carry TPR/TPO cycles and study the metallic surface area /degree of dispersion of $\mathrm{Ni}$-nanoparticles if they insist to consider this work to the catalysis community.

- We have previously carried TPR/TPO cycles in order to study the nature of Ni particles generated from the perovskite structure. As we expected the results showed the reduction of $\mathrm{Ni}$ species from the perovskite structure and after an oxidation step the results showed only the reduction of $\mathrm{Ni}$ from $\mathrm{NiO}$ over $\mathrm{LaAlO}_{3}$ support. These experiments also evidenced an increase of metallic Ni particle size. This study was not included in this work because the aim of this work was to study the influence of reduction variables in the generated particles size.

This kind of solids was also previously used in the steam reforming reaction and published in a previous paper. [F. N. Aguero, M. R. Morales, S. Larrégola, E. M. Izurieta, E. Lopez, L. E. Cadús. Int. J of Hy Energ 40(2015)15510-15520. http://dx.doi.org/10.1016/j.ijhydene.2015.08.051]. These solids showed to be active and stable in the studied reaction demonstrating that the efficiency of the generated $\mathrm{Ni}$ particles with small size from a perovskite structure was higher than that obtained from $\mathrm{Ni}$ particles generated from an impregnation process which presented even higher dispertion of metal particles. However, this work is focused in the study of $\mathrm{Ni}$ generated particles size in different conditions of synthesis. The present work provides among its highlights the perspective that it is possible to control the exsolution and therefore the size of the catalytic centers. Additionally, the smaller the Ni loads, the less the imbalance in the support structure will be. As it is mentioned in the article, this study can lay the groundwork for the design of the catalysts even used in other reactions that employ metal catalysts.

-In addition English revision is necessary

- An intense revision of the manuscript in order to check the grammar and the spelling errors have been made following the reviewer suggestions.

Reviewer \#2: The authors prepared the LaAl1-xNixO3 perovskite oxides via a citrate route, investigated the $\mathrm{Ni}$ exsolution processes, characterized their physicochemical properties. This work contains some new results and may be 
accepted for publication. However, the authors should modify their manuscript before acceptance for publication according to the following comments:

1. Why do the authors think that the Ni particles were anchored to the support? What is the evidence?

We could observed from TEM study, Figure 6 in the article that Ni particles are anchored to the support. The transition of phases are clear in the image and this is explained in the work.

Usually, the reduction gas mixture is $\mathrm{H}_{2}$ and $\mathrm{Ar}$ (balance). Why do the authors use $\mathrm{H}_{2}$ and $\mathrm{N}_{2}$ (balance) in the reduction processes?

The balance of the reduction mixture could be done with any inert gas, $\mathrm{N}_{2}$ is one of the gases usually used as it is Ar or He.

2. After reduction of LaAl1-xNixO3, the lattice positions occupied by the original $\mathrm{Ni}$ atoms became cationic vacancies? If the pervoskite oxide was changed to $\mathrm{LaAlO} 3$ after reduction, there would be presence of $\mathrm{La} 2 \mathrm{O} 3$ impurity phase.

The exolution of $\mathrm{Ni}$ particles certainly generates the presence of cationic vacancies. In fact after the reduction process only metallic $\mathrm{Ni}$ and $\mathrm{LaAlO} 3$ phases were detected.

3. There are a large number of inappropriate English words or expressions in the manuscript. The authors should carefully polish the English of the whole manuscript.

- An intense revision of the manuscript in order to check the grammar and the spelling errors have been made following the reviewer suggestions 


\title{
Surface Nickel particles generated by exsolution from a perovskite
}

\author{
structure
}

\author{
Fabiola N. Agüero ${ }^{1 *}$, Ana M. Beltrán², María Asunción Fernández ${ }^{3}$, Luis E. Cadús ${ }^{1}$ \\ 1. Instituto de Investigaciones en Tecnología Química (INTEQUI), UNSL - \\ CONICET, Almirante Brown 1455, 5700 San Luis, Argentina.
}

2. Departamento de Ingeniería y Ciencia de los Materiales y del Transporte, Escuela Politécnica Superior, Universidad de Sevilla, Virgen de África 7, 41011 Sevilla, Spain

3. Instituto de Ciencia de Materiales de Sevilla, (CSIC-Univ. Sevilla), Avda. Américo Vespucio 49, 41092 Sevilla, Spain

\begin{abstract}
$\mathrm{LaAl}_{1-\mathrm{x}} \mathrm{Ni}_{\mathrm{x}} \mathrm{O}_{3}$ (with $\mathrm{x}=0.05$ and 0.2 ) perovskite oxides were successfully synthesized and its behavior under reduction atmosphere was studied. HRTEM and STEM studies, coupled to HAADF and EDX detection, allowed to evidence the Ni exsolution process to the surface of the solid and to build nano-catalytic centers. The size of these centers is independent of the reduction conditions in the range studied. The high specific surface of the raw material, its porosity and the structure defects could be responsible of the low temperature at which the exsolution process starts. The content of Ni dopants allows the control of $\mathrm{Ni}$ centers size on the surface and the synthesis method provides Ninanoparticles strongly anchored to the resultant support.
\end{abstract}


Keywords: Ni particles, perovskites, exsolution process, reduction conditions, TEM

\section{Introduction}

Heterogeneous catalysis is a complex phenomenon that studies, both surface architecture of catalysts and, in many cases, the interaction of the catalytic centers with the support. Surface architecture involves size of catalytic centers, dispersion of metals and repartition between two or more metals. Stability of the catalytic centers could be strongly influenced by the interaction of the metals with the support [1]. The support could play an important role in redox processes of regeneration of the catalytic centers, in the control of deactivation process by carbon formation [2] or preventing the sintering of metallic particles [3].

$\mathrm{Ni}$ based catalysts have been widely used in steam reforming reactions due to the ability of Ni particles to break the C-C bonds. However, these catalysts suffer from several limitations that hinder their further application, including sintering of $\mathrm{Ni}$ particles agglomeration and carbon coking [2]. Steam reforming is a structure sensible reaction [4], thus, the activity and selectivity of catalysts can be improved by controlling the size of $\mathrm{Ni}$ centers on the surface. This objective can be rise by decorating the surface with metal nanoparticles. Traditionally, Ni particles are loaded to the support surface by chemical or physical deposition but such nanoparticles tend to sinter [5,6]. This problem would be solved with Ni particles strongly attached to the support and with a smaller size [7]. It is probable that if $\mathrm{Ni}$ exsolution is made from a host structure, Ni particles will be linked to the support and will improve the resistance to sinterisation. In addition, it is necessary to 
control the size of the formed Ni particles considering the synthesis and exsolution process parameters. The most relevant parameters are the catalyst treatment atmosphere and $\mathrm{Ni}$ composition of the catalyst precursor. It is also important to note that a relatively high specific surface area is required since this material will be used as a catalyst and this area could modify the Ni exsolution process.

Perovskite type oxides have been widely used as catalysts in several reactions. Besides, many of these oxides have been used as precursor of catalysts considering it as a host structure of cations. [8,9]. In $\mathrm{ABB}^{\prime} \mathrm{O}_{3}$ mixed oxides perovskites, the exsolution process of $\mathrm{B}^{\prime}$ is favored in comparison with B cation, on the basis of their metallic character [10-12], elements with more metallic character tends to be eliminated to the surface because the Gibbs free energy change acts as the driving force. Thus, the catalyst design could be done considering this characteristic. However, it is necessary to have a stable host structure where A and B sites remain oxidized during reduction, in order to maintain the perovskite phase as catalyst support. In literature, there are evidences of the exsolution process. Arrive et al. [7] worked with a $\mathrm{La}_{0.5} \mathrm{Sr}_{0.5} \mathrm{Ti}_{0.75} \mathrm{Ni}_{0.25} \mathrm{O}_{3}$ perovskite which is used as electrode for solid oxide cell; they showed a thermogravimetric analysis in $\mathrm{Ar} / \mathrm{H}_{2}$ atmosphere, where a significant weight loss could be observed at $1000{ }^{\circ} \mathrm{C}$ corresponding to oxygen departures related to $\mathrm{Ni}$ and/or $\mathrm{Ti}$ cation reduction. They showed that Ni nanoparticles were obtained after a reduction process at $1200{ }^{\circ} \mathrm{C}$. At this temperature there is an important specific surface area decrease and, then, the material is not suitable for catalysis. Thommy et al. [13] compared impregnation versus an exsolution process in order to improve electrocatalytic properties of $\mathrm{LaSrCrMnO}_{3}$ based anodes. They showed that under hydrogen atmosphere and, in comparison to impregnation approach, exsolution does not offer significant advantages with regard to the polarization phenomena. However, the exsolution 
method produces dispersed nanoparticles firmly anchored to grain surface which minimizes nanoparticles agglomeration during ageing. In a previous work, the same authors used exsolution method to improve the electrocatalytic properties of $\mathrm{La}_{0.75} \mathrm{Sr}_{0.25} \mathrm{Cr}_{0.5} \mathrm{Mn}_{0.5-}$ ${ }_{x} \mathrm{Ni}_{\mathrm{x}} \mathrm{O}_{3-\mathrm{x}}[14]$.

There are many works in literature about obtaining metal nanoparticles highly dispersed on a support. However, there are still some questions that deserve to be responded: is it possible to achieve good results by growing up Ni particles from a host structure? Is there any influence of the parameters of the exsolution process on the final architecture of the catalytic surface? Is there any influence of the morphology of the precursor on the exsolution process?

The insights developed in this work may help to find further strategies for catalyst design. The aim is to study the parameters involved in the Ni exsolution process from a stable perovskite structure, $\mathrm{LaAlO}_{3}$. By this way, a higher knowledge in the design of a catalyst with defined characteristics would be reached. Even if this study has been made on a steam reforming catalyst, it could be eventually used as reference for other metallic catalyst.

\section{Experimental}

\subsection{Catalysts preparation}

$\mathrm{LaAl}_{1-\mathrm{y}} \mathrm{Ni}_{\mathrm{y}} \mathrm{O}_{3}(\mathrm{y}=0,0.05,0.2)$ perovskites were prepared by the citrate method [15]. $\mathrm{La}\left(\mathrm{NO}_{3}\right)_{3} \times 6 \mathrm{H}_{2} \mathrm{O}, \mathrm{Al}\left(\mathrm{NO}_{3}\right)_{3} \times 6 \mathrm{H}_{2} \mathrm{O}, \mathrm{Ni}\left(\mathrm{NO}_{3}\right)_{2}$ were dissolved in water and were added to an excess citric acid solution. The solution was slowly evaporated under vacuum in a rotavapor at $75{ }^{\circ} \mathrm{C}$ until a gel was obtained. This gel was dried in a vacuum oven, slowly increasing the temperature to $200{ }^{\circ} \mathrm{C}$ and keeping this temperature overnight, to produce a 
solid amorphous citrate precursor. The resulting precursor was milled and then calcined in air at $800{ }^{\circ} \mathrm{C}$ for $2 \mathrm{~h}$. The samples were named LaNiy, with $\mathrm{y}=0.05$ and 0.2.

In order to generate $\mathrm{Ni}$ particles, samples were submitted to a reduction process. The reducing gas was a mixture of 5 vol $\% \mathrm{H}_{2} / \mathrm{N}_{2}$, at a total flow rate of $30 \mathrm{~mL} \mathrm{~min}{ }^{-1}$. The temperature was increased from room temperature to 650 or $750{ }^{\circ} \mathrm{C}$ with a heating rate of 5,10 or $15^{\circ} \mathrm{C} \min ^{-1}$ maintaining this temperature for 30 or $60 \mathrm{~min}$. Table 1 summaries the conditions of the reduced samples.

\subsection{Samples Characterization}

\subsubsection{BET Specific Surface Area Measurements (SBET)}

The specific surface area of the samples was calculated by the BET method from the nitrogen adsorption isotherms obtained at $77 \mathrm{~K}$. A Gemini V from Micromeritics apparatus was used.

\subsubsection{X-ray Diffraction (XRD)}

XRD patterns were obtained by using a Rigaku diffractometer operated at $30 \mathrm{kV}$ and 25 $\mathrm{mA}$ by employing $\mathrm{Cu} \mathrm{K} \alpha$ radiation with Nickel filter $(\lambda=0.15418 \mathrm{~nm})$.

\subsubsection{X-ray Photoelectron Spectroscopy (XPS)}

XPS data were obtained with a Multitecnic UniSpecs equipment with a dual X ray source of $\mathrm{Mg} / \mathrm{Al}$ and an hemispheric analyzer PHOIBOS 150. A pass energy of $30 \mathrm{eV}$ and an $\mathrm{Al}$ anode operated at $100 \mathrm{~W}$ was used. The pressure was kept under $29 \times 10^{-8}$ mbar 


\subsubsection{Scanning-Transmission electron microscopy (STEM)}

TEM (Transmission Electron Microscopy) and STEM (Scanning-Transmission Electron Microscopy) studies were performed on a FEI Tecnai G2 F30 FEG (Field Emission Gun) microscope, equipped with a HAADF (High Angle Annular Dark Field) detector from Fischione Instruments. Images were obtained in TEM and HAADF-STEM mode at 300 $\mathrm{kV}$. Compositional analyses were performed by INCA X-Max 80 silicon drift detector (SDD) for Energy-Dispersive X-Ray (EDX). In particular, STEM-EDX line profiles were acquired across the nanoparticles to confirm their composition. For TEM observations, powdery samples were homogeneously dispersed in ethanol by ultrasound and dropped on a carbon film grid.

\section{Results and Discussion}

The base perovskite used in this work as host structure of $\mathrm{Ni}$ cations is a $\mathrm{LaAlO}_{3}$ phase (JCPDS file 31-22) with PM-3M space group and crystal planes with different polarity. In a previous work, it was demonstrated that $\mathrm{Ni}$ partial substitution in $\mathrm{B}$ position was successfully reached with a $20 \%$ molar substitution corresponding to a $\mathrm{Ni}$ weight concentration of $2.5 \%$ [16]. As it was above mentioned in the introduction section, the success in the catalyst design would be possible with a stable host structure, where A and B sites remain oxidized during reduction, in order to maintain the perovskite phase as catalyst support. The stability of the host structure was effectively proven. Figure 1 shows the XRD patterns of LaNi0.2 before and after the reduction process (LaNi0.2b). There are no differences between patterns. The stability of $\mathrm{LaAlO}_{3}$ phase is clear. Evidences of the presence of other phases products of the reduction process were not found. This fact can be 
explained from $\Delta \mathrm{G}$ values calculated with HSC Chemistry 5.1 program. This program calculates the $\Delta \mathrm{G}$ values considering the reduction atmosphere, the temperature and the cations involved (Figure 2). La and Al oxides are thermodynamically stable under reduction conditions. $\mathrm{La}$ and $\mathrm{Al}$ oxides have $\Delta \mathrm{G}>0$ at the simulated reduction conditions while nickel oxide is easily reducible. These data show that it is possible to imagine the exsolution of $\mathrm{Ni}$ in order to decorate the surface in a controlled manner.

There is another factor that can contribute Ni to overcome the energy barrier to arise the surface. Perovskites type solids are not homogeneous. In fact, Lanthanum based perovskites catalysts show a La/B cation atomic ratio determined from XPS higher than 1 [17]. Some authors have found that the stress and electronics effects could be responsible of difference in the concentration of dopant atoms at the surface with respect to the bulk [18]. This inhomogeneous concentration of the dopant atoms could help to drive the exsolution process. In addition, this particularity could aid to obtain isolated clusters of Ni strongly anchored to the support, the $\mathrm{LaAlO}_{3}$ perovskite. When the exsolution process starts, the concentration of dopant atoms increases at the vicinity of the surface [19]. A XPS study of perovskites after and before the reduction process could be useful to see this phenomenon. Actually, results showed in Table 2 indicate that after reduction the $\mathrm{Ni} /(\mathrm{La}+\mathrm{Al})$ atomic ratio increases from 0.04 to 0.09 for $\mathrm{LaNi0} .2$ and the $\mathrm{Ni} / \mathrm{Al}$ atomic ratio increases from 0.06 to 0.13 . These data indicate that $\mathrm{Ni}$ migrates to the surface enriching it, considering that XPS is a surface characterization of the most external layer of atoms. It is expected that Ni nanoparticles grow from the perovskite structure. This growth process starts when a nucleation center is obtained. But this process could take place both at the surface and in the bulk of the host material. According to Oh et al. [20] it is expected the nucleation of 
particles on the surface rather than in the bulk due to a smaller energy strain. The nucleation center could be responsible of an increase in the growth rate due to a hydrogen spill over generated on it. In addition, XRD pattern does not show any line corresponding to $\mathrm{Ni}$ diffraction. It is possible that $\mathrm{Ni}$-nanoparticles are very small and well-dispersed on the support surface as it is expected.

In order to obtain further information regarding the exsolution process and the formation of Ni-nanoparticles, a systematic TEM study was carried out, including HRTEM, HAADF-STEM and EDX-STEM. This TEM study was performed to address four issues: 1) morphological characterization of the catalyst and localization of the expected $\mathrm{Ni}$ nanoparticles; 2) influence of the reduction temperature, reduction time and heating rate on the nanoparticle size; 3) influence of the composition of $\mathrm{Ni}$ on the exsolved nanoparticles size; and finally: 4) Interaction of Ni-nanoparticles on the surface.

\section{Morphology of the catalyst and localization of the expected Ni-nanoparticles.}

Figure 3 shows HAADF-STEM images of the catalyst LaNi0.2 (a) before and (b), after reduction for LaNi0.2b. It is worth to mention that contrast on HAADF-STEM is proportional to $\mathrm{t} \cdot \mathrm{Z}^{\mathrm{n}}$, where $\mathrm{t}$ represents the specimen thickness crossed by the electron beam and $\mathrm{Z}$ is the averaged atomic mass of the material that interacts with the electron beam, with $\mathrm{n}$ ranging between 1.6 and 1.9 in most cases [21]. Therefore, the observed black areas should correspond to the presence of large pores, which are clearly observed in a wide range of sizes in the calcined sample.

Perovskites in this work were synthetized by the citrate method that provides solids with relatively high specific surface area (SSA), around $7 \mathrm{~m}^{2} \mathrm{~g}^{-1}$ (Table 2) in comparison to that obtained from ceramics methods with high calcination temperatures, generally higher than 
$1000{ }^{\circ} \mathrm{C}$. The exsolution process in this work was made at lower temperatures than those reported in several studies of solid oxide fuel cells materials. In those papers $[7,21]$ specific surface area are not reported but the high calcination and reduction temperatures are indicatives of a sintered material with small specific surface area. The SSA obtained for perovskites in this work is explained on the basis of a porous material, as it is clearly observed by TEM (for example, see Fig. 3-5). The porosity of sample would favor the Ni exsolution process due to the presence of high stress and electronics effects in a surface boundary. The stress at the surface could aid the exsolution process by a decrease of the driving force necessary to start it. Intrinsic properties such as surface features, mechanical stress and related strains [20] and the presence of defects as oxygen vacancies and dislocations $[22,23]$ could have an impact in the nucleation sites. This agrees with what we explained in a previous paper about the presence of oxygen vacancies in the $\mathrm{LaAlO}_{3}$ base perovskite, that reveals high content of $\mathrm{Os} / \mathrm{Ol}$ ratio and high temperatures reduction signals [16]. The morphology of the samples after reduction was also studied by HAADF-STEM (Fig. 3b), showing the same porous morphology. Ni-nanoparticles are expected to be in such reduced samples. The contrast on HAADF-STEM images may help to identify the Ninanoparticles. However, in this case, it is not so straight forward because, on one hand, there were Ni-metal nanoparticles $(\mathrm{Z}=28)$ and, on the other hand, $\mathrm{LaAlO}_{3}$ (average $\mathrm{Z} \approx$ 19). Furthermore, Ni-nanoparticles are supported on the perovskite. Considering all these aspects, in principle, Ni-nanoparticle may present a slightly brighter contrast than the perovskite. In fact, it has been possible to identify in HAADF images some brighter particles which may correspond to Ni-nanoparticles, as it is marked by an arrow in Fig. $3 b$. The presence of $\mathrm{Ni}$ in these nanoparticles have been confirmed by acquiring EDX-STEM line profiles across them. This strategy of analyses (EDX-STEM profiles) has been 
employed to investigate all the catalysts of this work, as it will be shown in the next sections.

\section{Effect of the reduction conditions on the Ni-nanoparticle size}

The influence of the reduction temperature, heating rate and reduction time in the nanoparticle size was studied. Figure 4 shows STEM-HAADF images, in which representative Ni-nanoparticles have been detected for LaNi0.2 samples after different reduction conditions. Particle size was measured on STEM-HAADF images, after identifying the Ni signal in the EDX line profile. The corresponding line profiles along one nanoparticle clearly show the strong increase of the Ni signal over them. Table 3 shows the results of Ni-nanoparticles average sizes obtained as a function of reduction treatment conditions. It can be observed that Ni-nanoparticles size practically does not change in the studied reduction conditions range. They are not completely round and their size is around $20 \mathrm{~nm}$. Gao et al. [19] also studied the influence of reduction variables in Ni-nanoparticle size from a $\mathrm{La}_{0.4} \mathrm{Sr}_{0.4} \mathrm{Sc}_{0.9} \mathrm{Ni}_{0.1} \mathrm{O}_{3-\delta}$ perovskite material. They found that at higher reduction time, higher particles size was observed. However, the curves of particle size as a function of reduction time became asymptotic at higher reduction time. In this work, the effect of low reduction time was studied considering the need to obtain the minimum particle size. Moreover, it must be considered the feasibility to carry out the reduction pre-treatment in the catalytic process. For this reason, the experiments were carried out under constant concentration of hydrogen conditions, 5 vol. $\% \mathrm{H}_{2} / \mathrm{N}_{2}$. Reduction temperatures were chosen considering TPR results trying to avoid a sinterization of catalyst. Probably, at these reduction conditions, only part of bulk $\mathrm{Ni}^{2+}$ has been transformed into $\mathrm{Ni}$-metal at the 
surface, although the main part was still in the perovskite structure. It is clearly observed that there is not a parametric sensibility of Ni-particle size in the range studied.

\section{Ni concentration in the host structure}

It is possible that the maximum size of Ni-nanoparticles depends on total amount of $\mathrm{Ni}$ atoms in the bulk material. In fact, Gao et al. have suggested, by DFT calculations, that the total amount of $\mathrm{Ni}$ could be a reasonable factor limiting the maximum size of the nanoparticles [19]. As it was above discussed, the size of particles does not depend on the reduction conditions used in this work. To prove the effect of $\mathrm{Ni}$ content on the host structure a LaNi0.05 perovskite was synthesized, reduced and observed by HRTEM and STEM. Figure 5 shows a STEM-HAADF image, together with the corresponding EDX-STEM line profile, of a representative Ni-nanoparticle located on the perovskite surface for the reduced LaNi0.05 sample. Already from the line profile along the nanoparticle it is clear, in comparison to Fig. 4, that nanoparticles are smaller. The estimated average value from the study of several nanoparticles is also included in Table 2. We found that the size of Ni centers on the surface is almost proportional to the Ni content. A quarter of Ni dopants gives centers that are almost a quarter smaller than those observed for LaNi0.2b.

\section{Interaction of $\mathrm{Ni}$-nanoparticles with the surface}

Figure 6 shows a HRTEM image of a representative small Ni-nanoparticle attached to the main bulk of the perovskite for the reduced LaNi0.2b sample. The lattice space of the perovskite bulk is clearly visible and the Filtered Fourier Transform (FFT) of the marked area shows spots corresponding to $\{010\}$ planes of the crystalline structure of the $\mathrm{LaAlO}_{3}$ 
base phase. The small Ni-nanoparticle appears anchored to the perovskite, also showing a crystalline structure, as seen in the HRTEM image and the FFT pattern. Nanoparticles are not round, instead, they appeared faceted to some extent. The analysis of the FFT patterns indicates that $\mathrm{Ni}$-nanoparticles can be oxidized to $\mathrm{NiO}$ on the surface as it may be expected due to the air exposure.

As it has been demonstrated by the STEM-EDX line profile analyses, the concentration of $\mathrm{Ni}$ in the nanoparticle is significantly higher than that on the host material. It is possible that the growth results from the diffusion of $\mathrm{Ni}^{2+}$ ions to the nanoparticle followed by the reduction to $\mathrm{Ni}$ metal. The $\mathrm{Ni}$ metal could activate hydrogen spill over to accelerate the process of reduction. As a result Ni-nanoparticles can be strongly anchored at the bulk perovskite grains, which would be very beneficial for their stability in reaction conditions.

\section{Conclusions}

$\mathrm{LaAl}_{1-\mathrm{x}} \mathrm{Ni}_{\mathrm{x}} \mathrm{O}_{3}$ perovskite oxides (with $\mathrm{x}=0.05$ and 0.2 ) were successfully synthesized and its behavior under reduction atmosphere was studied. HRTEM and HAADF-STEM studies, coupled to EDX detector, allowed evidencing the Ni exsolution process to the surface of the oxides to build nano-catalytic centers. The size of these centers did not depend on the reduction conditions for the studied range. This range was limited in order to obtain a material suitable for catalysis from the point of view of the morphology and the specific surface area.

The high specific surface of the raw material, its porosity and the structure defects could be responsible of the low temperature at which the exsolution process starts. The content of Ni dopants allows the control of $\mathrm{Ni}$ centers size on the surface and the synthesis method provides Ni-nanoparticles strongly anchored to the resultant support. 
Therefore, this study could give certain information about the design of nano-materials that could be used as catalysts for several reactions. In general, reactions in which metals particles with small nanoparticle size, highly dispersed and well anchored on a support, are necessary.

\section{References}

[1] S. Shaikhutdinov, Strong Metal-Support Interaction and Reactivity of Ultrathin Oxide Films, Catal. Letters 148(2028)2657-2635. https://doi.org/10.1007/s10562-018-2499-9

[2] A. Haryanto, S. Fernando, N. Murali, S. Adhikari, Current Status of Hydrogen Production Techniques by Steam Reforming of Ethanol: A Review, Energy Fuels, 19(2005)2098-2106. https://doi.org/10.1021/ef0500538.

[3] F. Frusteri, S. Freni Bio-ethanol, a suitable fuel to produce hydrogen for a molten carbonate fuel cell. J Power Sources, 173(2007)200-209. https://doi.org/10.1016/j.jpowsour.2007.04.065

[4] H.S. Bengaard, J.K. Norskov, J. Sehested, B.S. Clausen, L.P. Nielsen, A. M. Molenbroek, J.R Rostrup-NIELSEN. Steam Reforming and Graphite Formation on Ni Catalysts, J. Catal. 209(2002)365-384. https://doi.org/10.1006/jcat.2002.3579.

[5] T. Borowiecki, Nickel catalysts for steam reforming of hydrocarbons; size of crystallites and resistance to coking, Appl. Catal. 4(1982)223-231. https://doi.org/10.1016/0166$\underline{9834(82) 80104-8}$

[6] D. Neagu, G. Tsekouras, D.N. Miller, H. Menard, J.T. Irvine In situ growth of nanoparticles through control of non-stoichiometry. Nat. Chem., 5(2013)916-923. https://doi.org/10.1038/nchem.1773. 
[7] C. Arrivé, T. Delahaye, O. Joubert, G. Gauthier. Exsolution of nickel nanoparticles at the surface of a conducting titanate as potential hydrogen electrode material for solid oxide electrochemical cells. J. Power Sources, 223(2013)341-348. https://doi.org/10.1016/j.jpowsour.2012.09.062

[8] G. Valderrama, A. Kiennemann, C. Urbina de Navarro, M. Goldwasser. $\mathrm{LaNi}_{1-\mathrm{x}} \mathrm{Mn}_{\mathrm{x}} \mathrm{O}_{3}$ perovskite-type oxides as catalyst precursors for dry reforming of methane. Appl. Catal. A 565(2018)26-33. http://doi.org/10.1016/j.apcata.2018.07.039

[9] T. Wei, L. Jia, H. Zheng, B. Chi, J. Pu, J. Li. $\mathrm{LaMnO}_{3}$-based perovskite with in-situ exsolved Ni nanoparticles: a highly active, performance stable and coking resistant catalyst for $\mathrm{CO}_{2}$ dry reforming of $\mathrm{CH}_{4}$. Applied Catalysis A, General 564(2018)199-207. https://doi.org/10.1016/j.apcata.2018.07.031

[10] D. Neagu, G. Tsekouras, D.N. Miller, H. Menard, J.T. Irvine. In situ growth of nanoparticles through control of non-stoichiometry. Nat. Chem. 5(2013)916-923. http://doi.org/10.1038/NCHEM.1773

[11] Y. Nishihata, J. Mizuki, T. Akao, H. Tanaka, M. Uenishi, M. Kimura, T. Okamoto, N. Hamada. Self-regeneration of a Pd-perovskite catalyst for automotive emissions control. Nature 418 (2002) 164-167. https://doi.org/10.1038/nature00893.

[12] B. Madsen, W. Kobsiriphat, Y. Wang, L. Marks, S. Barnett. Nucleation of nanometerscale electrocatalyst particles in solid oxide fuel cell anodes. J. Power Sources 166 (2007) 64-67. https://doi.org/10.1016/j.jpowsour.2006.12.080.

[13] L. Thommy, O. Joubert, J. Hamon, M. T. Caldes. Impregnation versus exsolution: Using metal catalysts to improve electrocatalytic properties of LSCM-based anodes operating at $600{ }^{\circ} \mathrm{C}$. Int $\mathrm{J}$ Hydrogen Energy, 41 (2016) 14207-14216). https://doi.org/10.1016/j.ijhydene.2016.06.088 
[14] T. Jardiel, M.T. Caldes, F. Moser, J. Hamon, G. Gauthier, O. Joubert New SOFC electrode materials: the Ni-substituted LSCM-based compounds $\left(\mathrm{La}_{0.75} \mathrm{Sr}_{0.25}\right)\left(\mathrm{Cr}_{0.5} \mathrm{Mn}_{0.5-\mathrm{x}} \mathrm{Ni}_{\mathrm{x}}\right) \mathrm{O}_{3-\delta}$ and $\left(\mathrm{La}_{0.75} \mathrm{Sr}_{0.25}\right)\left(\mathrm{Cr}_{0.5-\mathrm{x}} \mathrm{Ni}_{\mathrm{x}} \mathrm{Mn}_{0.5}\right) \mathrm{O}_{3-\delta}$. Solid State Ionics, 181(2010)894-901. https://doi.org/10.1016/j.ssi.2010.05.012.

[15] P. Courty, H. Ajot, C. Marcilly, B. Delmon. Oxydes mixtes ou en solution solide sous forme très divisée obtenus par décomposition thermique de précurseurs amorphes. Power Technol. 7(1973)21. https://doi.org/10.1016/0032-5910(73)80005-1

[16] F. N. Aguero, M. R. Morales, S. Larrégola, E. M. Izurieta, E. Lopez, L. E. Cadús. La ${ }_{\mathrm{x}} \mathrm{Ca}_{\mathrm{x}} \mathrm{Al}_{1-\mathrm{y}} \mathrm{Ni}_{\mathrm{y}} \mathrm{O}_{3}$ perovskites used as precursors of nickel based catalysts for ethanol steam Reforming. Int. J of Hy Energ 40(2015)15510-15520. http://dx.doi.org/10.1016/j.ijhydene.2015.08.051 [17] N. A. Merino, B. P. Barbero, P. Grange, L. E. Cadús. $\mathrm{La}_{1-\mathrm{x}} \mathrm{Ca}_{\mathrm{x}} \mathrm{CoO}_{3}$ perovskite-type oxides: preparation, characterisation, stability, and catalytic potentiality for the total oxidation of propane. J of Catal. 231 (2005) 232-244. http://doi.org/doi:10.1016/j.jcat.2005.01.003. [18] I. Hamada, A.Uozumi,Y.Morikawa,A.Yanase,H.Katayama-Yoshida. A Density Functional Theory Study of Self-Regenerating Catalysts $\mathrm{LaFe}_{1-\mathrm{x}} \mathrm{M}_{\mathrm{x}} \mathrm{O}_{3-\mathrm{y}}(\mathrm{M}=\mathrm{Pd}, \mathrm{Rh}, \mathrm{Pt})$ J.Am. Chem. Soc. 133 (2011)18506-18509. http://doi.org/10.1021/ja110302t.

[19] Y. Gao, D. Chen, M. Saccoccio, Z. Lu, F. Ciucci. From material design to mechanism study: Nanoscale Ni exsolution on a highly active A-site deficient anode material for solid oxide fuel cells. http://dx.doi.org/10.1016/j.nanoen.2016.07.013. [20] T.-S.Oh, E.K.Rahani, D.Neagu, J.T.Irvine, V.B.Shenoy, R.J.Gorte, J.M.Vohs. Evidence and Model for Strain-Driven Release of Metal Nanocatalysts from Perovskites 
during Exsolution. J. Phys.Chem.Lett. 6 (2015)5106-5110.

http://doi.org/10.1021/acs.jpclett.5b02292

[21] P. Hartel, H. Rose, C. Dinges, Conditions and reasons for incoherent imaging in STEM, Ultramicroscopy. 63 (1996) 93-114. https://doi.org/10.1016/0304-3991(96)00020-4

[22] C.L. Kelchner,S.Plimpton,J.Hamilton. Dislocation nucleation and defect structure during surface indentation. Phys.Rev.B 58 (1998)11085.

https://doi.org/10.1103/PhysRevB.58.11085

[23] D. Neagu,G.Tsekouras,D.N.Miller,H.Menard,J.T.Irvine. In situ growth of nanoparticles through control of non-stoichiometry. Nat.Chem. 5 (2013)916-923. https://doi.org/10.1038/nchem.1773

\section{Acknowledgements}

The financial support from Universidad Nacional de San Luis, CONICET, ANPCyT is gratefully acknowledge. Spanish MINECO (grant CTQ2015-65918-R, EU co-financed by FEDER) and the CSIC (PIE-201760E002) financial support is also acknowledge. TEM

measurements were performed at the LANE, Laboratory of Nanoscopies and Spectroscopies, at the ICMS. 


\section{Table captions.}

Table 1: Conditions of the reduced samples.

Table 2: XPS of samples before and after the reduction treatments. $\mathrm{S}_{\mathrm{BET}}$ results.

Table 3: Ni particle mean size values determined by TEM analysis as a function of reduction conditions and $\mathrm{Ni}$ content. 
Table 1. Conditions of the reduced samples

\begin{tabular}{lccc}
\hline Sample & \multicolumn{3}{c}{ Reduction Conditions } \\
\cline { 2 - 4 } & $\mathrm{T}\left({ }^{\circ} \mathrm{C}\right)$ & Heating rate $\left({ }^{\circ} \mathrm{C} / \mathrm{min}\right)$ & $\mathrm{t}(\mathrm{min})$ \\
\hline LaNi0.2 a & 650 & 15 & 30 \\
LaNi0.2 b & 650 & 15 & 60 \\
LaNi0.2 c & 750 & 5 & 30 \\
LaNi0.2 d & 750 & 15 & 30 \\
LaNi0.05b & 650 & 15 & 60
\end{tabular}

Table 2. XPS of samples before and after the reduction treatments. $\mathrm{S}_{\mathrm{BET}}$ results.

\begin{tabular}{lccc}
\hline Sample & \multicolumn{2}{c}{ XPS Results } & $\begin{array}{c}\text { S } \\
\text { BET }\end{array}$ \\
\cline { 2 - 3 } & $\mathrm{Ni} /(\mathrm{La}+\mathrm{Al})$ & $\mathrm{Ni} / \mathrm{Al}$ & \\
\hline LaNi0.2 b & 0.09 & 0.13 & \\
LaNi0.2 & 0.04 & 0.06 & 7.4 \\
LaNi0.05 b & 0.06 & 0.10 & \\
LaNi0.05 & 0.05 & 0.10 & 6.3
\end{tabular}


Table 3. Ni particle mean size values determined by TEM analysis as a function of reduction conditions and $\mathrm{Ni}$ content.

\begin{tabular}{lcccc}
\hline Sample & \multicolumn{3}{c}{ Reduction Conditions } & \multirow{2}{*}{ Ni Particle Mean } \\
\cline { 2 - 4 } & $\mathrm{T}\left({ }^{\circ} \mathrm{C}\right)$ & $\mathrm{B}\left({ }^{\circ} \mathrm{C} / \mathrm{min}\right)$ & $\mathrm{t}(\mathrm{min})$ & size $(\mathrm{nm})$ \\
\hline LaNi0.2 a & 650 & 15 & 30 & 18.5 \\
LaNi0.2 b & 650 & 15 & 60 & 20 \\
LaNi0.2 c & 750 & 5 & 30 & 22 \\
LaNi0.2 d & 750 & 15 & 30 & 22 \\
LaNi0.05 b & 650 & 15 & 60 & 6
\end{tabular}




\section{Figure captions}

Figure 1: X-Ray diffraction patterns obtained for calcined samples.

Figure 2: Gibbs free energy for the reduction of $\mathrm{La}, \mathrm{Al}$ and $\mathrm{Ni}$ oxides to corresponding metals in $\mathrm{H}_{2}$. Generated by the HSC chemistry software. The reaction was considered as $1 / \mathrm{xM}_{\mathrm{x}} \mathrm{O}_{\mathrm{y}}+\mathrm{y} / \mathrm{xH}_{2}(\mathrm{~g})=\mathrm{M}+\mathrm{y} / \mathrm{xH}_{2} \mathrm{O}(\mathrm{g})$

Figure 3: STEM images of the samples: a) LaNi0.2 and b) LaNi0.2b

Figure 4: STEM images and EDX-STEM profiles of sample LaNi0.2 after different reduction conditions (a-d) according to Table 1 . The arrow indicates the direction along which the EDX profile was acquired over the particle.

Figure 5: STEM image and EDX-STEM profile taken over the particle (along the arrow direction) for the LaNi0.05b sample. Inset: detail of the EDX profile.

Figure 6: HRTEM image of sample LaNi0.2b. Insets: HRTEM detail of the Ni-nanoparticle and FFT of two marked areas on the Ni-nanoparticle and the perovskite. 
Figure 1

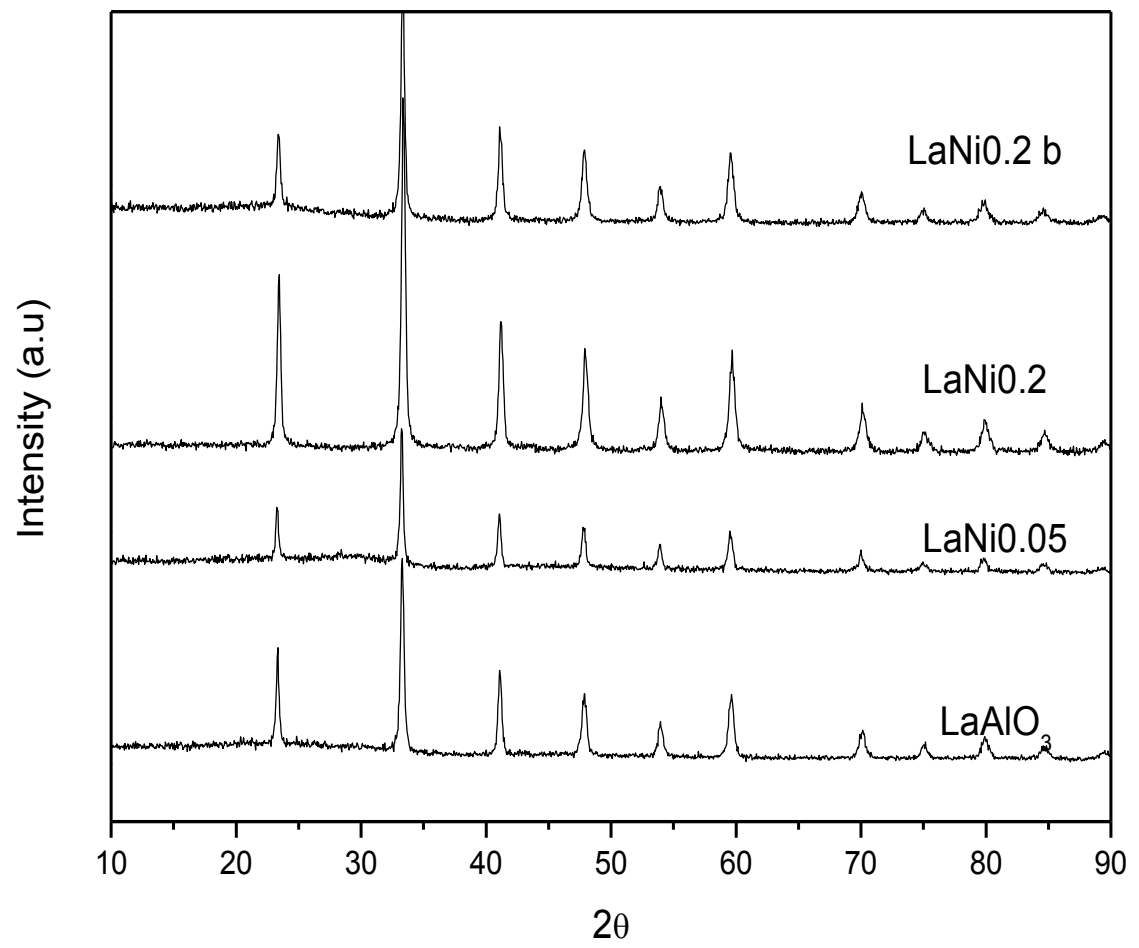


Figure 2

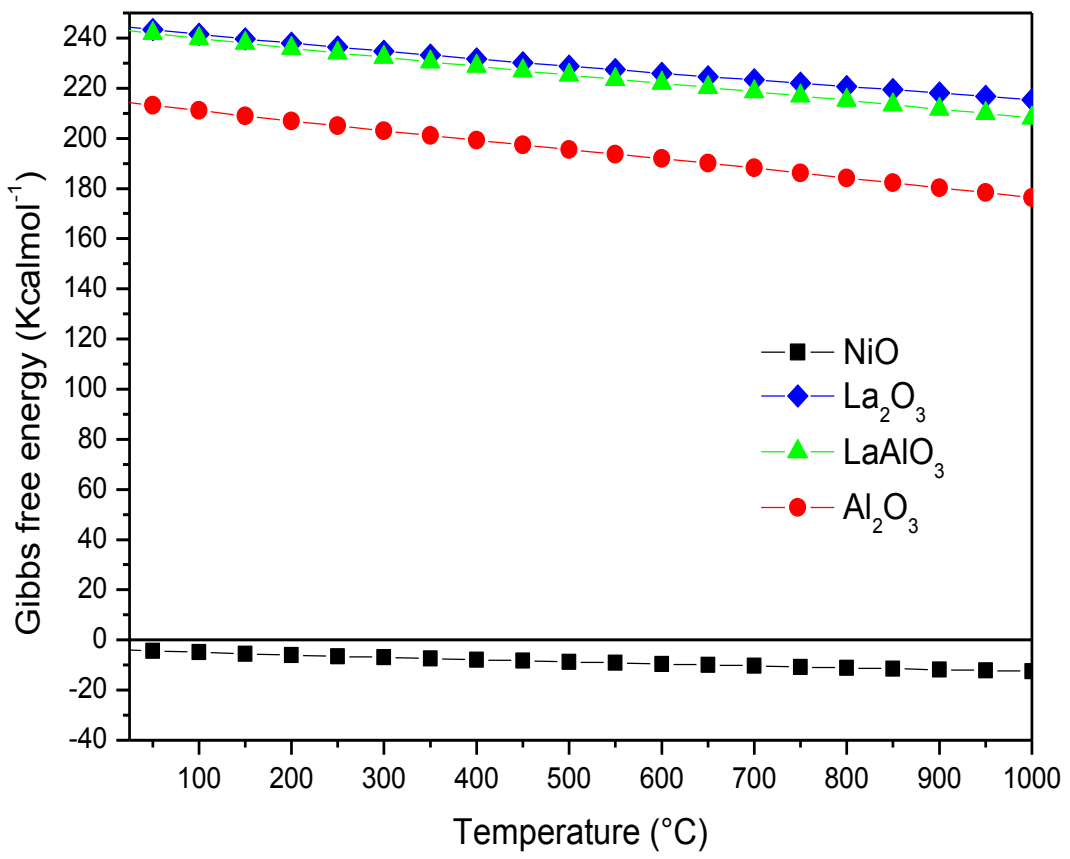


Figure 3

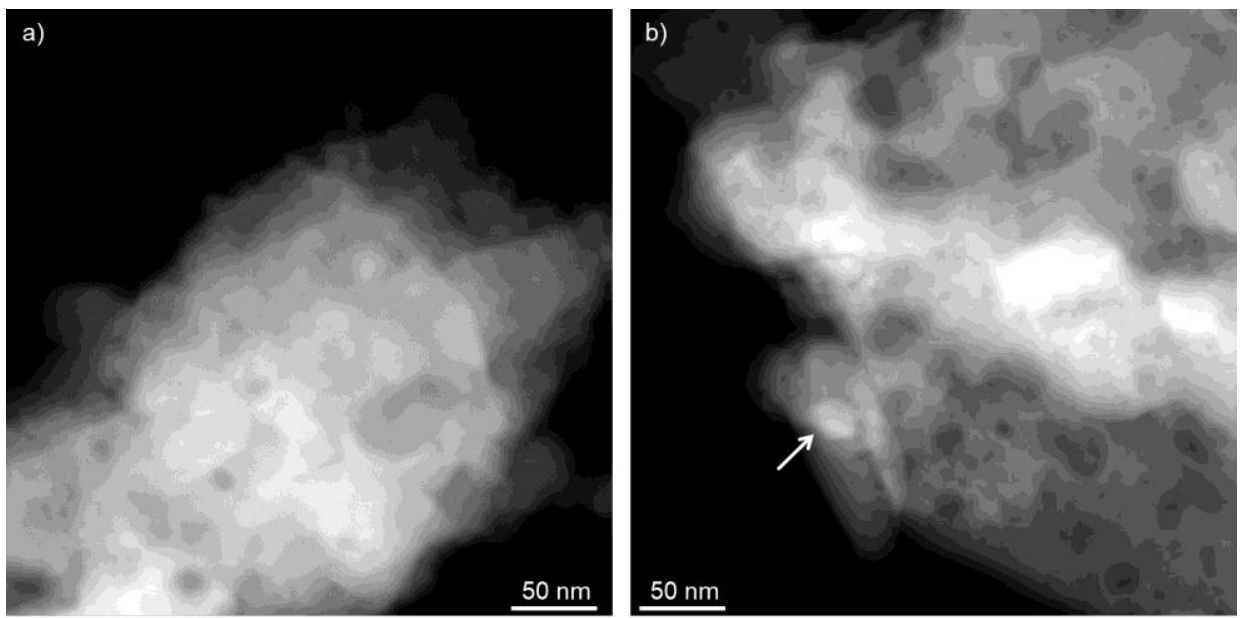

Figure 4
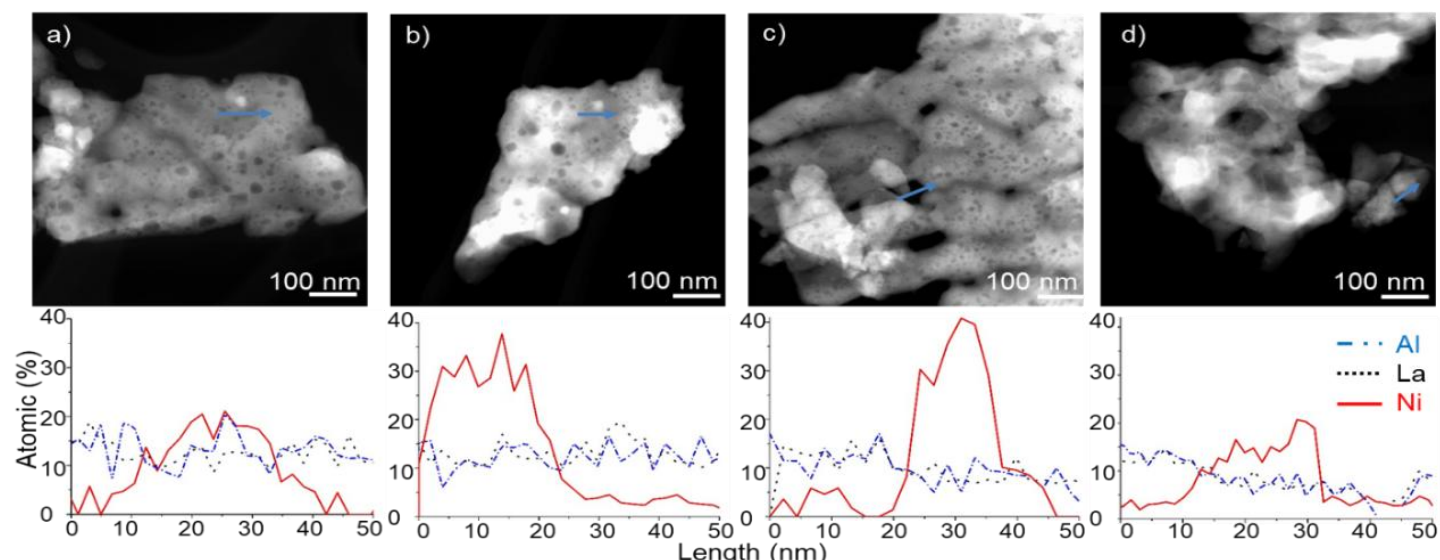
Figure 5
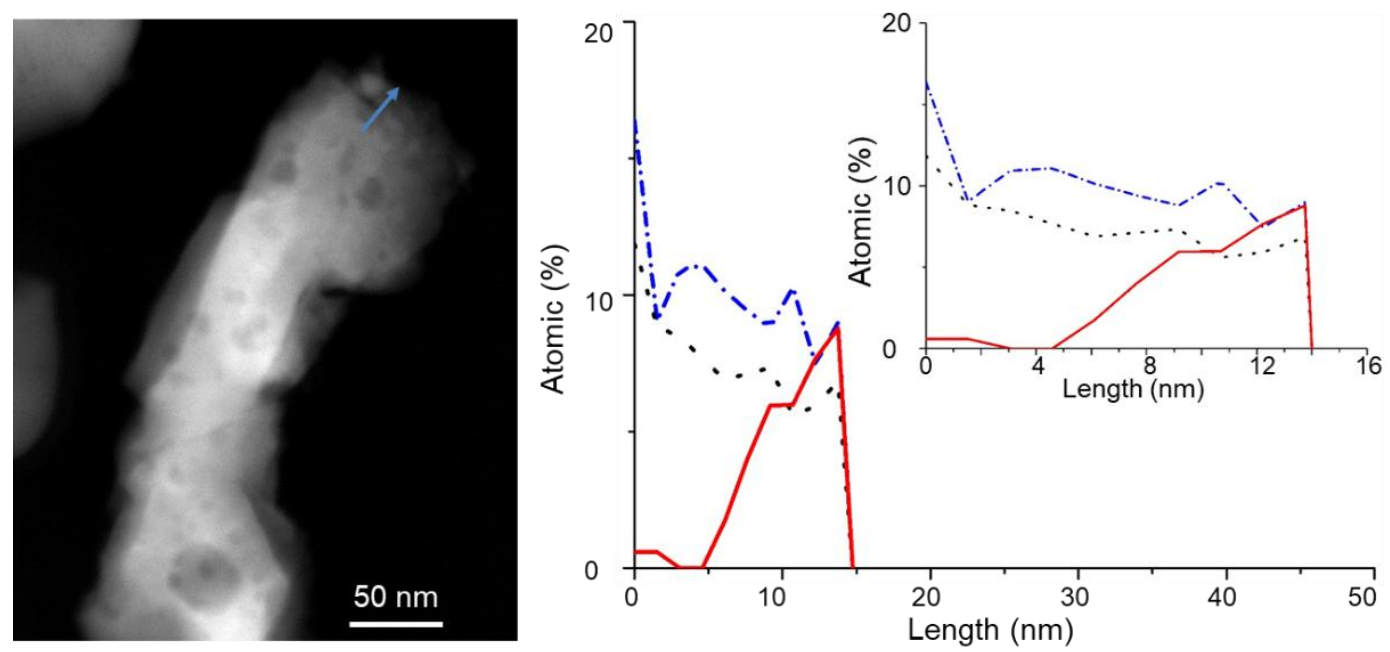

Figure 6

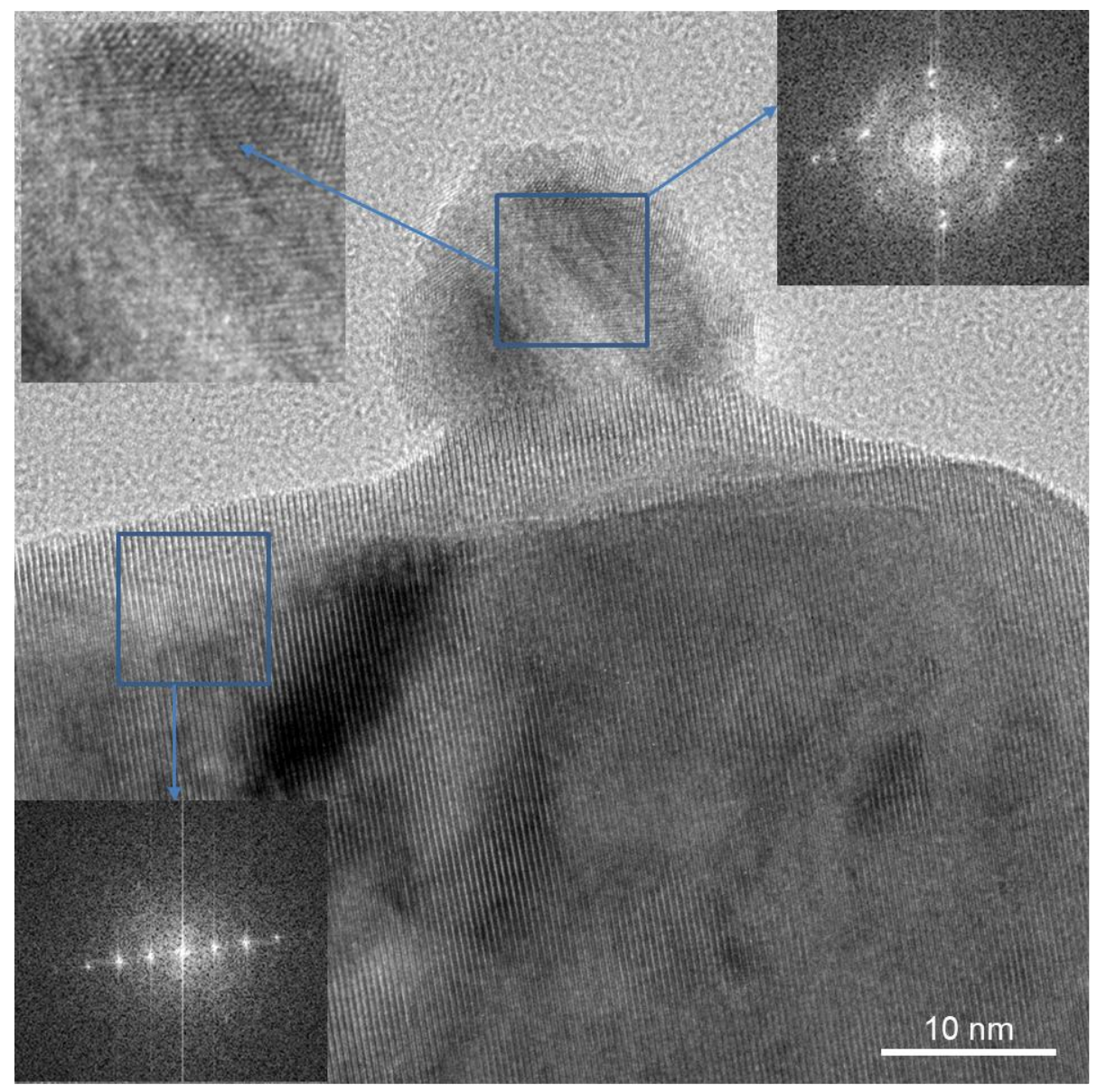




\title{
Surface Nickel particles generated by exsolution from a perovskite
}

\author{
structure
}

(Note: The corrections included in the revised version were of English language)

\author{
Fabiola N. Agüero ${ }^{1 *}$, Ana M. Beltrán ${ }^{2}$, María Asunción Fernández ${ }^{3}$, Luis E. Cadús ${ }^{1}$ \\ 1. Instituto de Investigaciones en Tecnología Química (INTEQUI), UNSL - \\ CONICET, Almirante Brown 1455, 5700 San Luis, Argentina.
}

2. Departamento de Ingeniería y Ciencia de los Materiales y del Transporte, Escuela Politécnica Superior, Universidad de Sevilla, Virgen de África 7, 41011 Sevilla, Spain

3. Instituto de Ciencia de Materiales de Sevilla, (CSIC-Univ. Sevilla), Avda. Américo Vespucio 49, 41092 Sevilla, Spain

\begin{abstract}
$\mathrm{LaAl}_{1-\mathrm{x}} \mathrm{Ni}_{\mathrm{x}} \mathrm{O}_{3}$ (with $\mathrm{x}=0.05$ and 0.2 ) perovskite oxides were successfully synthesized and its behavior under reduction atmosphere was studied. HRTEM and STEM studies, coupled to HAADF and EDX detection, allowed to evidence the Ni exsolution process to the surface of the solid and to build nano-catalytic centers. The size of these centers is independent of the reduction conditions in the range studied. The high specific surface of the raw material, its porosity and the structure defects could be responsible of the low temperature at which the exsolution process starts. The content of Ni dopants allows the control of $\mathrm{Ni}$ centers size on the surface and the synthesis method provides $\mathrm{Ni}$ nanoparticles strongly anchored to the resultant support.
\end{abstract}


Keywords: Ni particles, perovskites, exsolution process, reduction conditions, TEM

\section{Introduction}

Heterogeneous catalysis is a complex phenomenon that studies, both surface architecture of catalysts and, in many cases, the interaction of the catalytic centers with the support. Surface architecture involves size of catalytic centers, dispersion of metals and repartition between two or more metals. Stability of the catalytic centers could be strongly influenced by the interaction of the metals with the support [1]. The support could play an important role in redox processes of regeneration of the catalytic centers, in the control of deactivation process by carbon formation [2] or preventing the sintering of metallic particles [3].

Ni based catalysts have been widely used in steam reforming reactions due to the ability of $\mathrm{Ni}$ particles to break the C-C bonds. However, these catalysts suffer from several limitations that hinder their further application, including sintering of $\mathrm{Ni}$ particles agglomeration and carbon coking [2]. Steam reforming is a structure sensible reaction [4], thus, the activity and selectivity of catalysts can be improved by controlling the size of $\mathrm{Ni}$ centers on the surface. This objective can be rise by decorating the surface with metal nanoparticles. Traditionally, Ni particles are loaded to the support surface by chemical or physical deposition but such nanoparticles tend to sinter [5,6]. This problem would be solved with Ni particles strongly attached to the support and with a smaller size [7]. It is probable that if $\mathrm{Ni}$ exsolution is made from a host structure, Ni particles will be linked to 
the support and will improve the resistance to sinterisation. In addition, it is necessary to control the size of the formed Ni particles considering the synthesis and exsolution process parameters. The most relevant parameters are the catalyst treatment atmosphere and Ni composition of the catalyst precursor. It is also important to note that a relatively high specific surface area is required since this material will be used as a catalyst and this area could modify the Ni exsolution process.

Perovskite type oxides have been widely used as catalysts in several reactions. Besides, many of these oxides have been used as precursor of catalysts considering it as a host structure of cations. [8,9]. In $\mathrm{ABB}^{\prime} \mathrm{O}_{3}$ mixed oxides perovskites, the exsolution process of $\mathrm{B}^{\prime}$ is favored in comparison with B cation, on the basis of their metallic character [10-12], elements with more metallic character tends to be eliminated to the surface because the Gibbs free energy change acts as the driving force. Thus, the catalyst design could be done considering this characteristic. However, it is necessary to have a stable host structure where A and B sites remain oxidized during reduction, in order to maintain the perovskite phase as catalyst support. In literature, there are evidences of the exsolution process. Arrive et al. [7] worked with a $\mathrm{La}_{0.5} \mathrm{Sr}_{0.5} \mathrm{Ti}_{0.75} \mathrm{Ni}_{0.25} \mathrm{O}_{3}$ perovskite which is used as electrode for solid oxide cell; they showed a thermogravimetric analysis in $\mathrm{Ar} / \mathrm{H}_{2}$ atmosphere, where a significant weight loss could be observed at $1000{ }^{\circ} \mathrm{C}$ corresponding to oxygen departures related to $\mathrm{Ni}$ and/or $\mathrm{Ti}$ cation reduction. They showed that $\mathrm{Ni}$ nanoparticles were obtained after a reduction process at $1200{ }^{\circ} \mathrm{C}$. At this temperature there is an important specific surface area decrease and, then, the material is not suitable for catalysis. Thommy et al. [13] compared impregnation versus an exsolution process in order to improve electrocatalytic properties of $\mathrm{LaSrCrMnO}_{3}$ based anodes. They showed that under hydrogen atmosphere and, in comparison to impregnation approach, exsolution does not offer 
significant advantages with regard to the polarization phenomena. However, the exsolution method produces dispersed nanoparticles firmly anchored to grain surface which minimizes nanoparticles agglomeration during ageing. In a previous work, the same authors used exsolution method to improve the electrocatalytic properties of $\mathrm{La}_{0.75} \mathrm{Sr}_{0.25} \mathrm{Cr}_{0.5} \mathrm{Mn}_{0.5 \text { - }}$ ${ }_{x} \mathrm{Ni}_{\mathrm{x}} \mathrm{O}_{3-\mathrm{x}}[14]$.

There are many works in literature about obtaining metal nanoparticles highly dispersed on a support. However, there are still some questions that deserve to be responded: is it possible to achieve good results by growing up Ni particles from a host structure? Is there any influence of the parameters of the exsolution process on the final architecture of the catalytic surface? Is there any influence of the morphology of the precursor on the exsolution process?

The insights developed in this work may help to find further strategies for catalyst design. The aim is to study the parameters involved in the Ni exsolution process from a stable perovskite structure, $\mathrm{LaAlO}_{3}$. By this way, a higher knowledge in the design of a catalyst with defined characteristics would be reached. Even if this study has been made on a steam reforming catalyst, it could be eventually used as reference for other metallic catalyst.

\section{Experimental}

\subsection{Catalysts preparation}

$\mathrm{LaAl}_{1-\mathrm{y}} \mathrm{Ni}_{\mathrm{y}} \mathrm{O}_{3}(\mathrm{y}=0,0.05,0.2)$ perovskites were prepared by the citrate method [15]. $\mathrm{La}\left(\mathrm{NO}_{3}\right)_{3} \times 6 \mathrm{H}_{2} \mathrm{O}, \mathrm{Al}\left(\mathrm{NO}_{3}\right)_{3} \times 6 \mathrm{H}_{2} \mathrm{O}, \mathrm{Ni}\left(\mathrm{NO}_{3}\right)_{2}$ were dissolved in water and were added to an excess citric acid solution. The solution was slowly evaporated under vacuum in a rotavapor at $75{ }^{\circ} \mathrm{C}$ until a gel was obtained. This gel was dried in a vacuum oven, slowly increasing the temperature to $200{ }^{\circ} \mathrm{C}$ and keeping this temperature overnight, to produce a 
solid amorphous citrate precursor. The resulting precursor was milled and then calcined in air at $800{ }^{\circ} \mathrm{C}$ for $2 \mathrm{~h}$. The samples were named LaNiy, with $\mathrm{y}=0.05$ and 0.2.

In order to generate $\mathrm{Ni}$ particles, samples were submitted to a reduction process. The reducing gas was a mixture of 5 vol $\% \mathrm{H}_{2} / \mathrm{N}_{2}$, at a total flow rate of $30 \mathrm{~mL} \mathrm{~min}{ }^{-1}$. The temperature was increased from room temperature to 650 or $750{ }^{\circ} \mathrm{C}$ with a heating rate of 5,10 or $15^{\circ} \mathrm{C} \min ^{-1}$ maintaining this temperature for 30 or $60 \mathrm{~min}$. Table 1 summaries the conditions of the reduced samples.

\subsection{Samples Characterization}

\subsubsection{BET Specific Surface Area Measurements (SBET)}

The specific surface area of the samples was calculated by the BET method from the nitrogen adsorption isotherms obtained at $77 \mathrm{~K}$. A Gemini V from Micromeritics apparatus was used.

\subsubsection{X-ray Diffraction (XRD)}

XRD patterns were obtained by using a Rigaku diffractometer operated at $30 \mathrm{kV}$ and 25 $\mathrm{mA}$ by employing $\mathrm{Cu} \mathrm{K} \alpha$ radiation with Nickel filter $(\lambda=0.15418 \mathrm{~nm})$.

\subsubsection{X-ray Photoelectron Spectroscopy (XPS)}

XPS data were obtained with a Multitecnic UniSpecs equipment with a dual X ray source

of $\mathrm{Mg} / \mathrm{Al}$ and an hemispheric analyzer PHOIBOS 150. A pass energy of $30 \mathrm{eV}$ and an $\mathrm{Al}$ anode operated at $100 \mathrm{~W}$ was used. The pressure was kept under $29 \times 10^{-8}$ mbar 


\subsubsection{Scanning-Transmission electron microscopy (STEM)}

TEM (Transmission Electron Microscopy) and STEM (Scanning-Transmission Electron Microscopy) studies were performed on a FEI Tecnai G2 F30 FEG (Field Emission Gun) microscope, equipped with a HAADF (High Angle Annular Dark Field) detector from Fischione Instruments. Images were obtained in TEM and HAADF-STEM mode at 300 $\mathrm{kV}$. Compositional analyses were performed by INCA X-Max 80 silicon drift detector (SDD) for Energy-Dispersive X-Ray (EDX). In particular, STEM-EDX line profiles were acquired across the nanoparticles to confirm their composition. For TEM observations, powdery samples were homogeneously dispersed in ethanol by ultrasound and dropped on a carbon film grid.

\section{Results and Discussion}

The base perovskite used in this work as host structure of $\mathrm{Ni}$ cations is a $\mathrm{LaAlO}_{3}$ phase (JCPDS file 31-22) with PM-3M space group and crystal planes with different polarity. In a previous work, it was demonstrated that $\mathrm{Ni}$ partial substitution in $\mathrm{B}$ position was successfully reached with a $20 \%$ molar substitution corresponding to a $\mathrm{Ni}$ weight concentration of $2.5 \%$ [16]. As it was above mentioned in the introduction section, the success in the catalyst design would be possible with a stable host structure, where A and B sites remain oxidized during reduction, in order to maintain the perovskite phase as catalyst support. The stability of the host structure was effectively proven. Figure 1 shows the XRD patterns of LaNi0.2 before and after the reduction process (LaNi0.2b). There are no differences between patterns. The stability of $\mathrm{LaAlO}_{3}$ phase is clear. Evidences of the presence of other phases products of the reduction process were not found. This fact can be 
explained from $\Delta \mathrm{G}$ values calculated with HSC Chemistry 5.1 program. This program calculates the $\Delta \mathrm{G}$ values considering the reduction atmosphere, the temperature and the cations involved (Figure 2). La and Al oxides are thermodynamically stable under reduction conditions. $\mathrm{La}$ and $\mathrm{Al}$ oxides have $\Delta \mathrm{G}>0$ at the simulated reduction conditions while nickel oxide is easily reducible. These data show that it is possible to imagine the exsolution of $\mathrm{Ni}$ in order to decorate the surface in a controlled manner.

There is another factor that can contribute Ni to overcome the energy barrier to arise the surface. Perovskites type solids are not homogeneous. In fact, Lanthanum based perovskites catalysts show a La/B cation atomic ratio determined from XPS higher than 1 [17]. Some authors have found that the stress and electronics effects could be responsible of difference in the concentration of dopant atoms at the surface with respect to the bulk [18]. This inhomogeneous concentration of the dopant atoms could help to drive the exsolution process. In addition, this particularity could aid to obtain isolated clusters of Ni strongly anchored to the support, the $\mathrm{LaAlO}_{3}$ perovskite. When the exsolution process starts, the concentration of dopant atoms increases at the vicinity of the surface [19]. A XPS study of perovskites after and before the reduction process could be useful to see this phenomenon. Actually, results showed in Table 2 indicate that after reduction the $\mathrm{Ni} /(\mathrm{La}+\mathrm{Al})$ atomic ratio increases from 0.04 to 0.09 for $\mathrm{LaNi0} .2$ and the $\mathrm{Ni} / \mathrm{Al}$ atomic ratio increases from 0.06 to 0.13 . These data indicate that $\mathrm{Ni}$ migrates to the surface enriching it, considering that XPS is a surface characterization of the most external layer of atoms. It is expected that Ni nanoparticles grow from the perovskite structure. This growth process starts when a nucleation center is obtained. But this process could take place both at the surface and in the bulk of the host material. According to Oh et al. [20] it is expected the nucleation of 
particles on the surface rather than in the bulk due to a smaller energy strain. The nucleation center could be responsible of an increase in the growth rate due to a hydrogen spill over generated on it. In addition, XRD pattern does not show any line corresponding to $\mathrm{Ni}$ diffraction. It is possible that $\mathrm{Ni}$-nanoparticles are very small and well-dispersed on the support surface as it is expected.

In order to obtain further information regarding the exsolution process and the formation of Ni-nanoparticles, a systematic TEM study was carried out, including HRTEM, HAADF-STEM and EDX-STEM. This TEM study was performed to address four issues: 1) morphological characterization of the catalyst and localization of the expected $\mathrm{Ni}$ nanoparticles; 2) influence of the reduction temperature, reduction time and heating rate on the nanoparticle size; 3) influence of the composition of $\mathrm{Ni}$ on the exsolved nanoparticles size; and finally: 4) Interaction of Ni-nanoparticles on the surface.

\section{Morphology of the catalyst and localization of the expected Ni-nanoparticles.}

Figure 3 shows HAADF-STEM images of the catalyst LaNi0.2 (a) before and (b), after reduction for LaNi0.2b. It is worth to mention that contrast on HAADF-STEM is proportional to $\mathrm{t} \cdot \mathrm{Z}^{\mathrm{n}}$, where $\mathrm{t}$ represents the specimen thickness crossed by the electron beam and $\mathrm{Z}$ is the averaged atomic mass of the material that interacts with the electron beam, with $\mathrm{n}$ ranging between 1.6 and 1.9 in most cases [21]. Therefore, the observed black areas should correspond to the presence of large pores, which are clearly observed in a wide range of sizes in the calcined sample.

Perovskites in this work were synthetized by the citrate method that provides solids with relatively high specific surface area (SSA), around $7 \mathrm{~m}^{2} \mathrm{~g}^{-1}$ (Table 2) in comparison to that obtained from ceramics methods with high calcination temperatures, generally higher than 
$1000{ }^{\circ} \mathrm{C}$. The exsolution process in this work was made at lower temperatures than those reported in several studies of solid oxide fuel cells materials. In those papers $[7,21]$ specific surface area are not reported but the high calcination and reduction temperatures are indicatives of a sintered material with small specific surface area. The SSA obtained for perovskites in this work is explained on the basis of a porous material, as it is clearly observed by TEM (for example, see Fig. 3-5). The porosity of sample would favor the Ni exsolution process due to the presence of high stress and electronics effects in a surface boundary. The stress at the surface could aid the exsolution process by a decrease of the driving force necessary to start it. Intrinsic properties such as surface features, mechanical stress and related strains [20] and the presence of defects as oxygen vacancies and dislocations $[22,23]$ could have an impact in the nucleation sites. This agrees with what we explained in a previous paper about the presence of oxygen vacancies in the $\mathrm{LaAlO}_{3}$ base perovskite, that reveals high content of $\mathrm{Os} / \mathrm{Ol}$ ratio and high temperatures reduction signals [16]. The morphology of the samples after reduction was also studied by HAADF-STEM (Fig. 3b), showing the same porous morphology. Ni-nanoparticles are expected to be in such reduced samples. The contrast on HAADF-STEM images may help to identify the Ninanoparticles. However, in this case, it is not so straight forward because, on one hand, there were Ni-metal nanoparticles $(\mathrm{Z}=28)$ and, on the other hand, $\mathrm{LaAlO}_{3}$ (average $\mathrm{Z} \approx$ 19). Furthermore, Ni-nanoparticles are supported on the perovskite. Considering all these aspects, in principle, Ni-nanoparticle may present a slightly brighter contrast than the perovskite. In fact, it has been possible to identify in HAADF images some brighter particles which may correspond to Ni-nanoparticles, as it is marked by an arrow in Fig. $3 b$. The presence of $\mathrm{Ni}$ in these nanoparticles have been confirmed by acquiring EDX-STEM line profiles across them. This strategy of analyses (EDX-STEM profiles) has been 
employed to investigate all the catalysts of this work, as it will be shown in the next sections.

\section{Effect of the reduction conditions on the Ni-nanoparticle size}

The influence of the reduction temperature, heating rate and reduction time in the nanoparticle size was studied. Figure 4 shows STEM-HAADF images, in which representative Ni-nanoparticles have been detected for LaNi0.2 samples after different reduction conditions. Particle size was measured on STEM-HAADF images, after identifying the Ni signal in the EDX line profile. The corresponding line profiles along one nanoparticle clearly show the strong increase of the Ni signal over them. Table 3 shows the results of Ni-nanoparticles average sizes obtained as a function of reduction treatment conditions. It can be observed that Ni-nanoparticles size practically does not change in the studied reduction conditions range. They are not completely round and their size is around $20 \mathrm{~nm}$. Gao et al. [19] also studied the influence of reduction variables in Ni-nanoparticle size from a $\mathrm{La}_{0.4} \mathrm{Sr}_{0.4} \mathrm{Sc}_{0.9} \mathrm{Ni}_{0.1} \mathrm{O}_{3-\delta}$ perovskite material. They found that at higher reduction time, higher particles size was observed. However, the curves of particle size as a function of reduction time became asymptotic at higher reduction time. In this work, the effect of low reduction time was studied considering the need to obtain the minimum particle size. Moreover, it must be considered the feasibility to carry out the reduction pre-treatment in the catalytic process. For this reason, the experiments were carried out under constant concentration of hydrogen conditions, 5 vol. $\% \mathrm{H}_{2} / \mathrm{N}_{2}$. Reduction temperatures were chosen considering TPR results trying to avoid a sinterization of catalyst. Probably, at these reduction conditions, only part of bulk $\mathrm{Ni}^{2+}$ has been transformed into $\mathrm{Ni}$-metal at the 
surface, although the main part was still in the perovskite structure. It is clearly observed that there is not a parametric sensibility of Ni-particle size in the range studied.

\section{Ni concentration in the host structure}

It is possible that the maximum size of Ni-nanoparticles depends on total amount of $\mathrm{Ni}$ atoms in the bulk material. In fact, Gao et al. have suggested, by DFT calculations, that the total amount of $\mathrm{Ni}$ could be a reasonable factor limiting the maximum size of the nanoparticles [19]. As it was above discussed, the size of particles does not depend on the reduction conditions used in this work. To prove the effect of $\mathrm{Ni}$ content on the host structure a LaNi0.05 perovskite was synthesized, reduced and observed by HRTEM and STEM. Figure 5 shows a STEM-HAADF image, together with the corresponding EDX-STEM line profile, of a representative Ni-nanoparticle located on the perovskite surface for the reduced LaNi0.05 sample. Already from the line profile along the nanoparticle it is clear, in comparison to Fig. 4, that nanoparticles are smaller. The estimated average value from the study of several nanoparticles is also included in Table 2. We found that the size of Ni centers on the surface is almost proportional to the Ni content. A quarter of Ni dopants gives centers that are almost a quarter smaller than those observed for LaNi0.2b.

\section{Interaction of $\mathrm{Ni}$-nanoparticles with the surface}

Figure 6 shows a HRTEM image of a representative small Ni-nanoparticle attached to the main bulk of the perovskite for the reduced LaNi0.2b sample. The lattice space of the perovskite bulk is clearly visible and the Filtered Fourier Transform (FFT) of the marked area shows spots corresponding to $\{010\}$ planes of the crystalline structure of the $\mathrm{LaAlO}_{3}$ 
base phase. The small Ni-nanoparticle appears anchored to the perovskite, also showing a crystalline structure, as seen in the HRTEM image and the FFT pattern. Nanoparticles are not round, instead, they appeared faceted to some extent. The analysis of the FFT patterns indicates that $\mathrm{Ni}$-nanoparticles can be oxidized to $\mathrm{NiO}$ on the surface as it may be expected due to the air exposure.

As it has been demonstrated by the STEM-EDX line profile analyses, the concentration of $\mathrm{Ni}$ in the nanoparticle is significantly higher than that on the host material. It is possible that the growth results from the diffusion of $\mathrm{Ni}^{2+}$ ions to the nanoparticle followed by the reduction to $\mathrm{Ni}$ metal. The $\mathrm{Ni}$ metal could activate hydrogen spill over to accelerate the process of reduction. As a result Ni-nanoparticles can be strongly anchored at the bulk perovskite grains, which would be very beneficial for their stability in reaction conditions.

\section{Conclusions}

$\mathrm{LaAl}_{1-\mathrm{x}} \mathrm{Ni}_{\mathrm{x}} \mathrm{O}_{3}$ perovskite oxides (with $\mathrm{x}=0.05$ and 0.2 ) were successfully synthesized and its behavior under reduction atmosphere was studied. HRTEM and HAADF-STEM studies, coupled to EDX detector, allowed evidencing the Ni exsolution process to the surface of the oxides to build nano-catalytic centers. The size of these centers did not depend on the reduction conditions for the studied range. This range was limited in order to obtain a material suitable for catalysis from the point of view of the morphology and the specific surface area.

The high specific surface of the raw material, its porosity and the structure defects could be responsible of the low temperature at which the exsolution process starts. The content of Ni dopants allows the control of $\mathrm{Ni}$ centers size on the surface and the synthesis method provides Ni-nanoparticles strongly anchored to the resultant support. 
Therefore, this study could give certain information about the design of nano-materials that could be used as catalysts for several reactions. In general, reactions in which metals particles with small nanoparticle size, highly dispersed and well anchored on a support, are necessary.

\section{References}

[1] S. Shaikhutdinov, Strong Metal-Support Interaction and Reactivity of Ultrathin Oxide Films, Catal. Letters 148(2028)2657-2635. https://doi.org/10.1007/s10562-018-2499-9

[2] A. Haryanto, S. Fernando, N. Murali, S. Adhikari, Current Status of Hydrogen Production Techniques by Steam Reforming of Ethanol: A Review, Energy Fuels, 19(2005)2098-2106. https://doi.org/10.1021/ef0500538.

[3] F. Frusteri, S. Freni Bio-ethanol, a suitable fuel to produce hydrogen for a molten carbonate fuel cell. J Power Sources, 173(2007)200-209. https://doi.org/10.1016/j.jpowsour.2007.04.065

[4] H.S. Bengaard, J.K. Norskov, J. Sehested, B.S. Clausen, L.P. Nielsen, A. M. Molenbroek, J.R Rostrup-NIELSEN. Steam Reforming and Graphite Formation on Ni Catalysts, J. Catal. 209(2002)365-384. https://doi.org/10.1006/jcat.2002.3579.

[5] T. Borowiecki, Nickel catalysts for steam reforming of hydrocarbons; size of crystallites and resistance to coking, Appl. Catal. 4(1982)223-231. https://doi.org/10.1016/0166$\underline{9834(82) 80104-8}$

[6] D. Neagu, G. Tsekouras, D.N. Miller, H. Menard, J.T. Irvine In situ growth of nanoparticles through control of non-stoichiometry. Nat. Chem., 5(2013)916-923. https://doi.org/10.1038/nchem.1773. 
[7] C. Arrivé, T. Delahaye, O. Joubert, G. Gauthier. Exsolution of nickel nanoparticles at the surface of a conducting titanate as potential hydrogen electrode material for solid oxide electrochemical cells. J. Power Sources, 223(2013)341-348. https://doi.org/10.1016/j.jpowsour.2012.09.062

[8] G. Valderrama, A. Kiennemann, C. Urbina de Navarro, M. Goldwasser. $\mathrm{LaNi}_{1-\mathrm{x}} \mathrm{Mn}_{\mathrm{x}} \mathrm{O}_{3}$ perovskite-type oxides as catalyst precursors for dry reforming of methane. Appl. Catal. A 565(2018)26-33. http://doi.org/10.1016/j.apcata.2018.07.039

[9] T. Wei, L. Jia, H. Zheng, B. Chi, J. Pu, J. Li. $\mathrm{LaMnO}_{3}$-based perovskite with in-situ exsolved Ni nanoparticles: a highly active, performance stable and coking resistant catalyst for $\mathrm{CO}_{2}$ dry reforming of $\mathrm{CH}_{4}$. Applied Catalysis A, General 564(2018)199-207. https://doi.org/10.1016/j.apcata.2018.07.031

[10] D. Neagu, G. Tsekouras, D.N. Miller, H. Menard, J.T. Irvine. In situ growth of nanoparticles through control of non-stoichiometry. Nat. Chem. 5(2013)916-923. http://doi.org/10.1038/NCHEM.1773

[11] Y. Nishihata, J. Mizuki, T. Akao, H. Tanaka, M. Uenishi, M. Kimura, T. Okamoto, N. Hamada. Self-regeneration of a Pd-perovskite catalyst for automotive emissions control. Nature 418 (2002) 164-167. https://doi.org/10.1038/nature00893.

[12] B. Madsen, W. Kobsiriphat, Y. Wang, L. Marks, S. Barnett. Nucleation of nanometerscale electrocatalyst particles in solid oxide fuel cell anodes. J. Power Sources 166 (2007) 64-67. https://doi.org/10.1016/j.jpowsour.2006.12.080.

[13] L. Thommy, O. Joubert, J. Hamon, M. T. Caldes. Impregnation versus exsolution: Using metal catalysts to improve electrocatalytic properties of LSCM-based anodes operating at $600{ }^{\circ} \mathrm{C}$. Int $\mathrm{J}$ Hydrogen Energy, 41 (2016) 14207-14216). https://doi.org/10.1016/j.ijhydene.2016.06.088 
[14] T. Jardiel, M.T. Caldes, F. Moser, J. Hamon, G. Gauthier, O. Joubert New SOFC electrode materials: the Ni-substituted LSCM-based compounds $\left(\mathrm{La}_{0.75} \mathrm{Sr}_{0.25}\right)\left(\mathrm{Cr}_{0.5} \mathrm{Mn}_{0.5-\mathrm{x}} \mathrm{Ni}_{\mathrm{x}}\right) \mathrm{O}_{3-\delta}$ and $\left(\mathrm{La}_{0.75} \mathrm{Sr}_{0.25}\right)\left(\mathrm{Cr}_{0.5-\mathrm{x}} \mathrm{Ni}_{\mathrm{x}} \mathrm{Mn}_{0.5}\right) \mathrm{O}_{3-\delta}$. Solid State Ionics, 181(2010)894-901. https://doi.org/10.1016/j.ssi.2010.05.012.

[15] P. Courty, H. Ajot, C. Marcilly, B. Delmon. Oxydes mixtes ou en solution solide sous forme très divisée obtenus par décomposition thermique de précurseurs amorphes. Power Technol. 7(1973)21. https://doi.org/10.1016/0032-5910(73)80005-1

[16] F. N. Aguero, M. R. Morales, S. Larrégola, E. M. Izurieta, E. Lopez, L. E. Cadús. La ${ }_{\mathrm{x}} \mathrm{Ca}_{\mathrm{x}} \mathrm{Al}_{1-\mathrm{y}} \mathrm{Ni}_{\mathrm{y}} \mathrm{O}_{3}$ perovskites used as precursors of nickel based catalysts for ethanol steam Reforming. Int. J of Hy Energ 40(2015)15510-15520. http://dx.doi.org/10.1016/j.ijhydene.2015.08.051 [17] N. A. Merino, B. P. Barbero, P. Grange, L. E. Cadús. $\mathrm{La}_{1-\mathrm{x}} \mathrm{Ca}_{\mathrm{x}} \mathrm{CoO}_{3}$ perovskite-type oxides: preparation, characterisation, stability, and catalytic potentiality for the total oxidation of propane. J of Catal. 231 (2005) 232-244. http://doi.org/doi:10.1016/j.jcat.2005.01.003. [18] I. Hamada, A.Uozumi,Y.Morikawa,A.Yanase,H.Katayama-Yoshida. A Density Functional Theory Study of Self-Regenerating Catalysts $\mathrm{LaFe}_{1-\mathrm{x}} \mathrm{M}_{\mathrm{x}} \mathrm{O}_{3-\mathrm{y}}(\mathrm{M}=\mathrm{Pd}, \mathrm{Rh}, \mathrm{Pt})$ J.Am. Chem. Soc. 133 (2011)18506-18509. http://doi.org/10.1021/ja110302t.

[19] Y. Gao, D. Chen, M. Saccoccio, Z. Lu, F. Ciucci. From material design to mechanism study: Nanoscale Ni exsolution on a highly active A-site deficient anode material for solid oxide fuel cells. http://dx.doi.org/10.1016/j.nanoen.2016.07.013. [20] T.-S.Oh, E.K.Rahani, D.Neagu, J.T.Irvine, V.B.Shenoy, R.J.Gorte, J.M.Vohs. Evidence and Model for Strain-Driven Release of Metal Nanocatalysts from Perovskites 
during Exsolution. J. Phys.Chem.Lett. 6 (2015)5106-5110.

http://doi.org/10.1021/acs.jpclett.5b02292

[21] P. Hartel, H. Rose, C. Dinges, Conditions and reasons for incoherent imaging in STEM, Ultramicroscopy. 63 (1996) 93-114. https://doi.org/10.1016/0304-3991(96)00020-4

[22] C.L. Kelchner,S.Plimpton,J.Hamilton. Dislocation nucleation and defect structure during surface indentation. Phys.Rev.B 58 (1998)11085.

https://doi.org/10.1103/PhysRevB.58.11085

[23] D. Neagu,G.Tsekouras,D.N.Miller,H.Menard,J.T.Irvine. In situ growth of nanoparticles through control of non-stoichiometry. Nat.Chem. 5 (2013)916-923. https://doi.org/10.1038/nchem.1773

\section{Acknowledgements}

The financial support from Universidad Nacional de San Luis, CONICET, ANPCyT is gratefully acknowledge. Spanish MINECO (grant CTQ2015-65918-R, EU co-financed by FEDER) and the CSIC (PIE-201760E002) financial support is also acknowledge. TEM

measurements were performed at the LANE, Laboratory of Nanoscopies and Spectroscopies, at the ICMS. 


\section{Table captions.}

Table 1: Conditions of the reduced samples.

Table 2: XPS of samples before and after the reduction treatments. $\mathrm{S}_{\mathrm{BET}}$ results.

Table 3: Ni particle mean size values determined by TEM analysis as a function of reduction conditions and $\mathrm{Ni}$ content. 
Table 1. Conditions of the reduced samples

\begin{tabular}{lccc}
\hline Sample & \multicolumn{3}{c}{ Reduction Conditions } \\
\cline { 2 - 4 } & $\mathrm{T}\left({ }^{\circ} \mathrm{C}\right)$ & Heating rate $\left({ }^{\circ} \mathrm{C} / \mathrm{min}\right)$ & $\mathrm{t}(\mathrm{min})$ \\
\hline LaNi0.2 a & 650 & 15 & 30 \\
LaNi0.2 b & 650 & 15 & 60 \\
LaNi0.2 c & 750 & 5 & 30 \\
LaNi0.2 d & 750 & 15 & 30 \\
LaNi0.05b & 650 & 15 & 60
\end{tabular}

Table 2. XPS of samples before and after the reduction treatments. $\mathrm{S}_{\mathrm{BET}}$ results.

\begin{tabular}{lccc}
\hline Sample & \multicolumn{2}{c}{ XPS Results } & $\begin{array}{c}\text { S } \\
\text { BET }\end{array}$ \\
\cline { 2 - 3 } & $\mathrm{Ni} /(\mathrm{La}+\mathrm{Al})$ & $\mathrm{Ni} / \mathrm{Al}$ & \\
\hline LaNi0.2 b & 0.09 & 0.13 & \\
LaNi0.2 & 0.04 & 0.06 & 7.4 \\
LaNi0.05 b & 0.06 & 0.10 & \\
LaNi0.05 & 0.05 & 0.10 & 6.3
\end{tabular}


Table 3. Ni particle mean size values determined by TEM analysis as a function of reduction conditions and $\mathrm{Ni}$ content.

\begin{tabular}{lcccc}
\hline Sample & \multicolumn{3}{c}{ Reduction Conditions } & \multirow{2}{*}{ Ni Particle Mean } \\
\cline { 2 - 4 } & $\mathrm{T}\left({ }^{\circ} \mathrm{C}\right)$ & $\mathrm{B}\left({ }^{\circ} \mathrm{C} / \mathrm{min}\right)$ & $\mathrm{t}(\mathrm{min})$ & size $(\mathrm{nm})$ \\
\hline LaNi0.2 a & 650 & 15 & 30 & 18.5 \\
LaNi0.2 b & 650 & 15 & 60 & 20 \\
LaNi0.2 c & 750 & 5 & 30 & 22 \\
LaNi0.2 d & 750 & 15 & 30 & 22 \\
LaNi0.05 b & 650 & 15 & 60 & 6
\end{tabular}




\section{Figure captions}

Figure 1: X-Ray diffraction patterns obtained for calcined samples.

Figure 2: Gibbs free energy for the reduction of $\mathrm{La}, \mathrm{Al}$ and $\mathrm{Ni}$ oxides to corresponding metals in $\mathrm{H}_{2}$. Generated by the HSC chemistry software. The reaction was considered as $1 / \mathrm{xM}_{\mathrm{x}} \mathrm{O}_{\mathrm{y}}+\mathrm{y} / \mathrm{xH}_{2}(\mathrm{~g})=\mathrm{M}+\mathrm{y} / \mathrm{xH}_{2} \mathrm{O}(\mathrm{g})$

Figure 3: STEM images of the samples: a) LaNi0.2 and b) LaNi0.2b

Figure 4: STEM images and EDX-STEM profiles of sample LaNi0.2 after different reduction conditions (a-d) according to Table 1 . The arrow indicates the direction along which the EDX profile was acquired over the particle.

Figure 5: STEM image and EDX-STEM profile taken over the particle (along the arrow direction) for the LaNi0.05b sample. Inset: detail of the EDX profile.

Figure 6: HRTEM image of sample LaNi0.2b. Insets: HRTEM detail of the Ni-nanoparticle and FFT of two marked areas on the Ni-nanoparticle and the perovskite. 
Figure 1

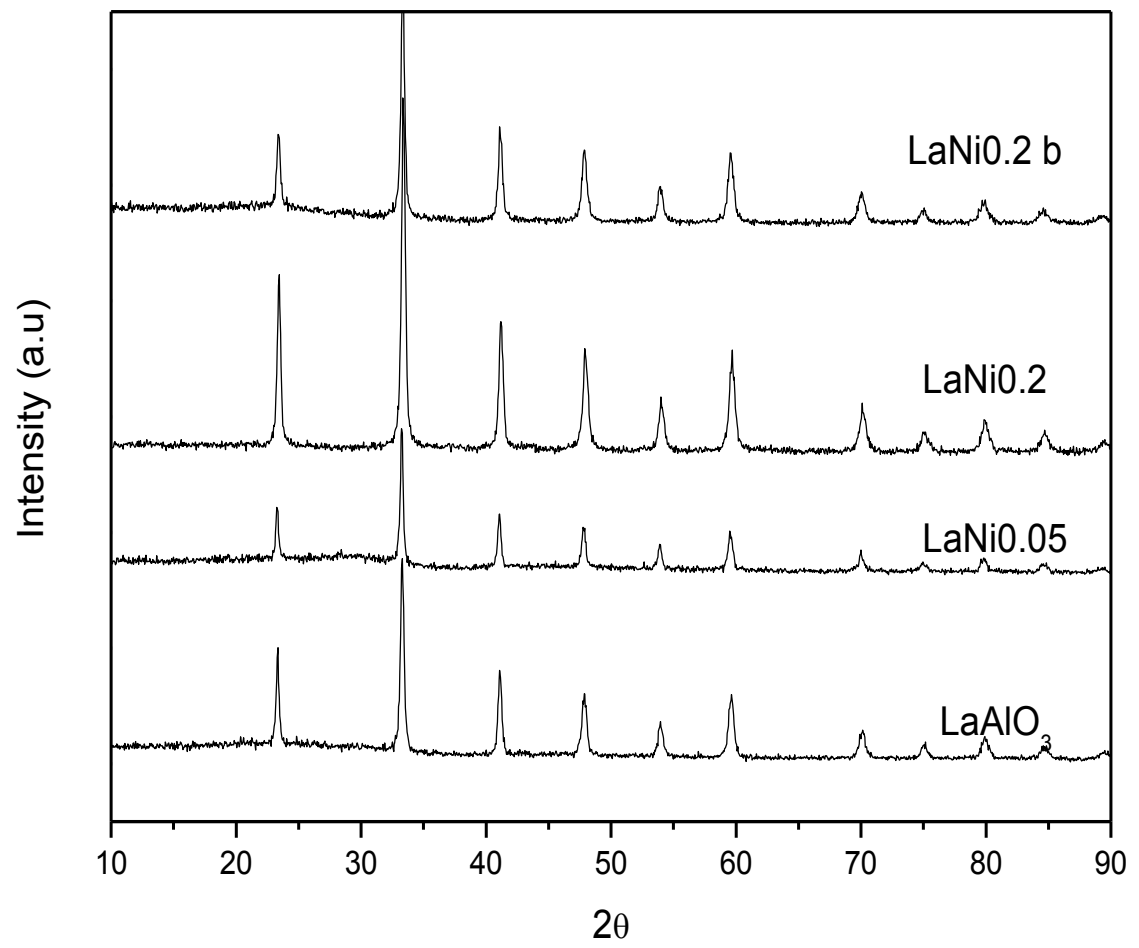


Figure 2

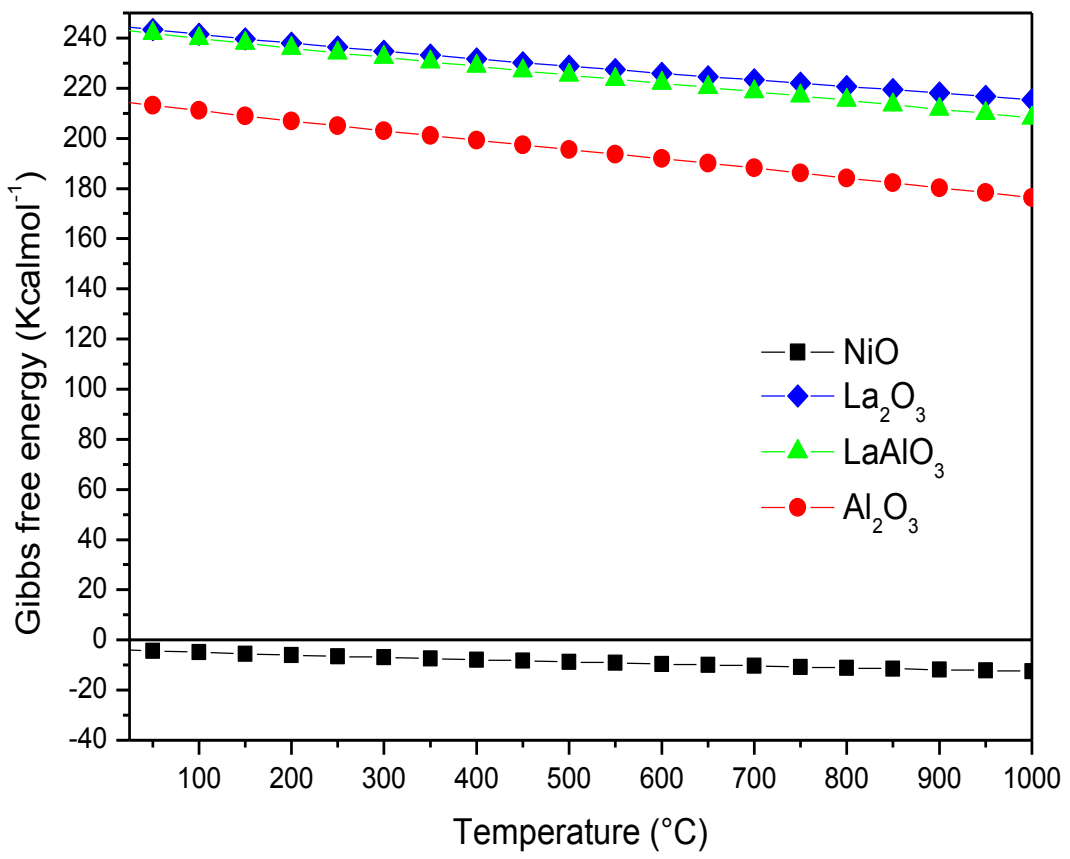


Figure 3

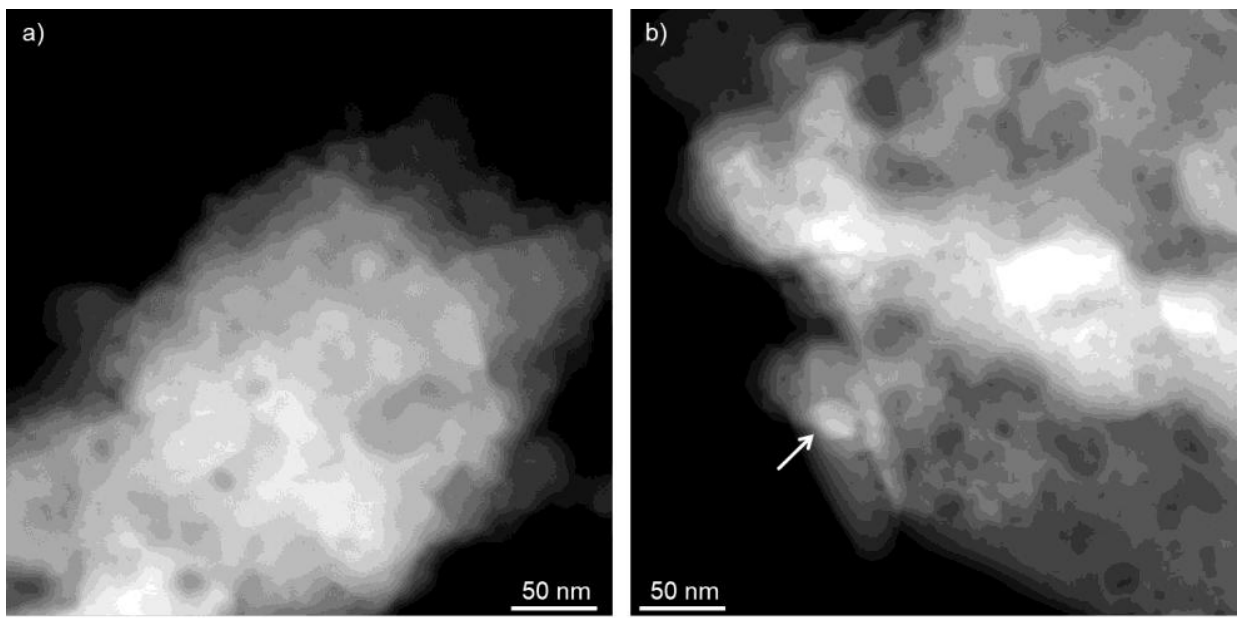

Figure 4
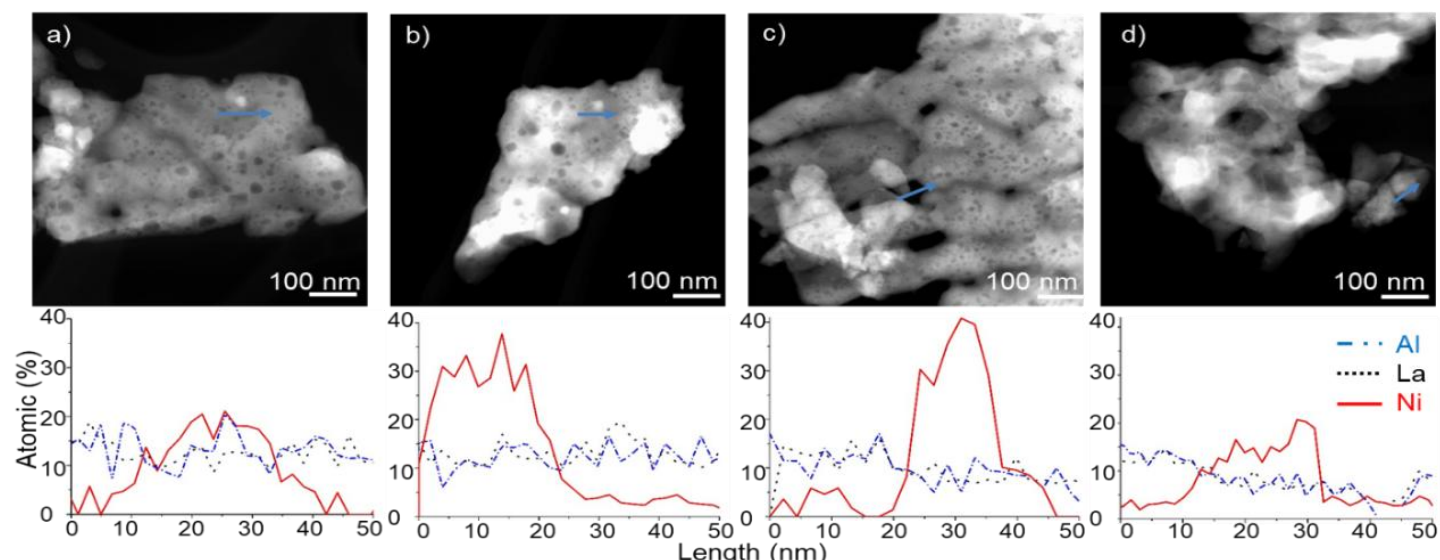
Figure 5
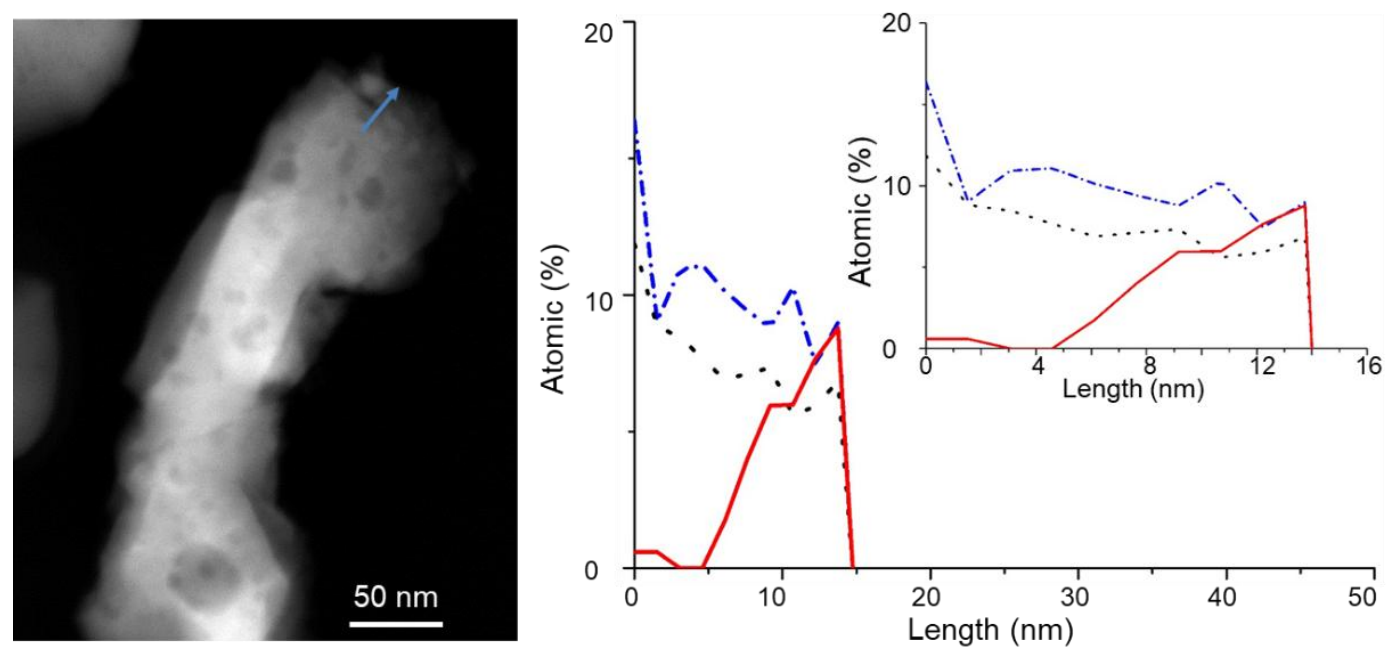

Figure 6

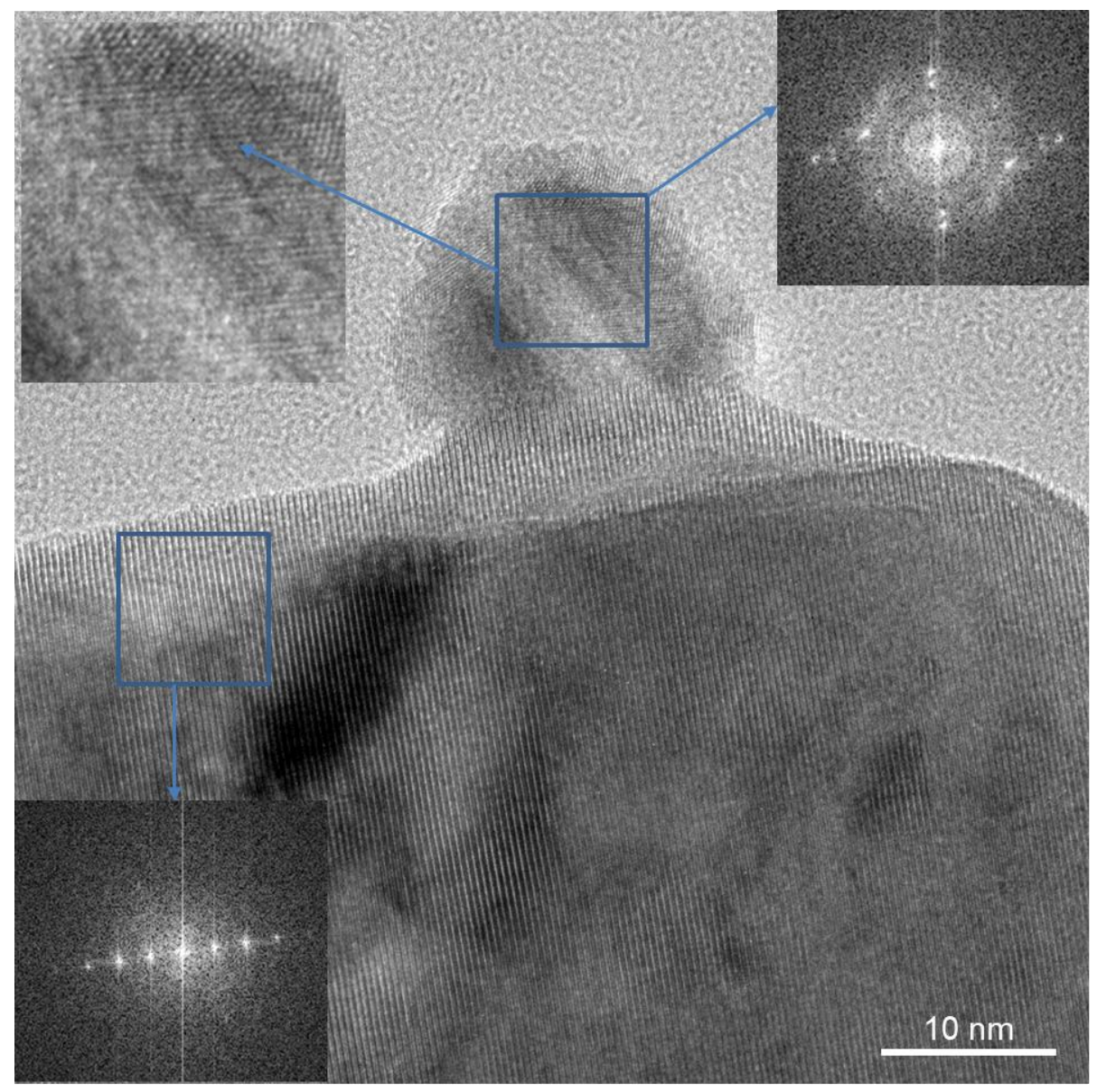




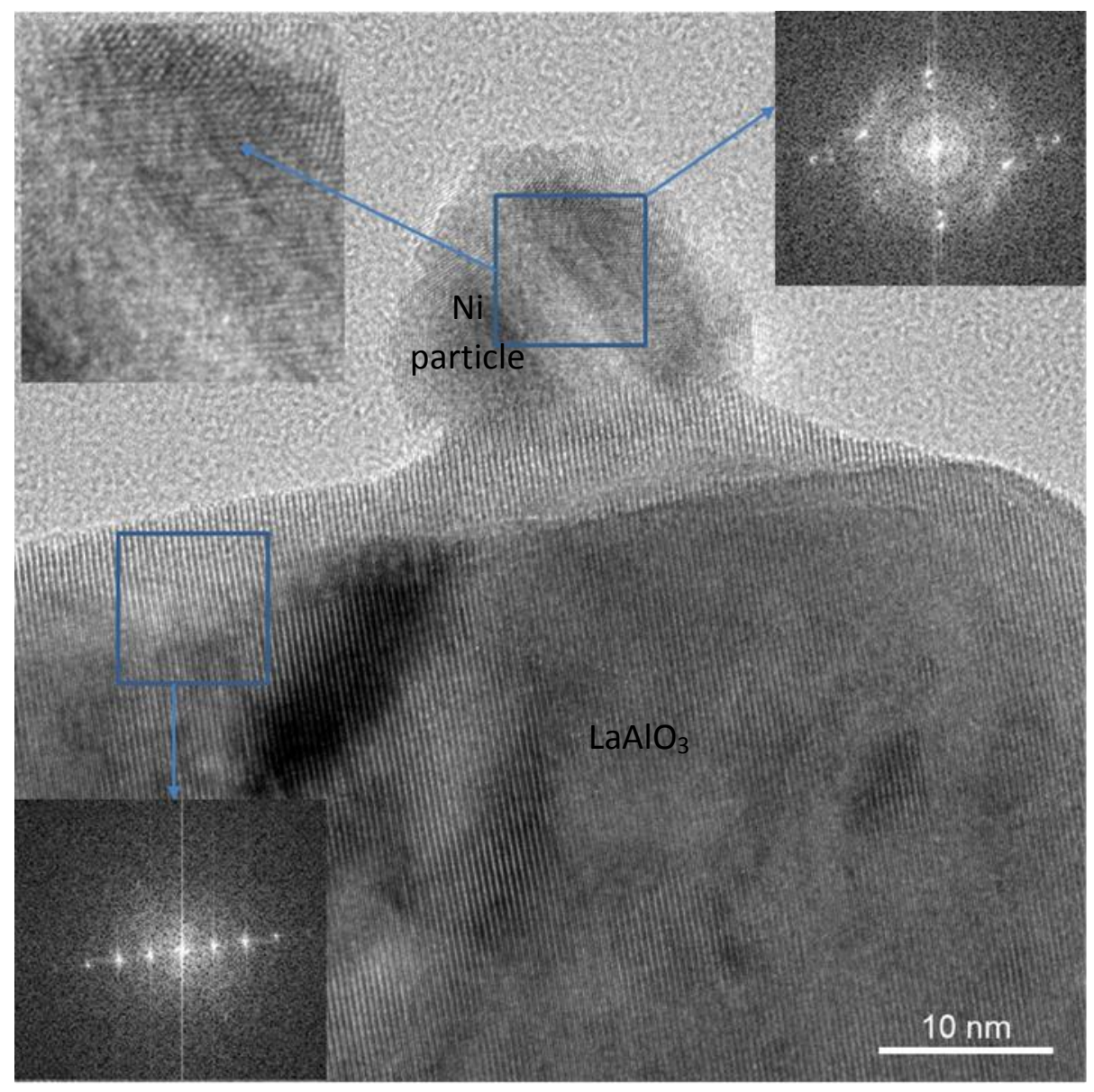


Ni-nanoparticle strongly anchored to the $\mathrm{LaAlO}_{3}$ support. 


\section{Highlights}

Perovskites behaviour under reducing atmosphere were studied.

Ni exsolution process to surface build nano-catalytic centers.

The size of Ni particles is independent on the reduction conditions in the range studied.

The content of Ni dopants allows the control of Ni centers size at the surface.

The synthesis method provides Ni-nanoparticles strongly anchored to the resultant support. 